Article

\title{
A Generalized Explicit Iterative Method for Solving Generalized Split Feasibility Problem and Fixed Point Problem in Real Banach Spaces
}

\author{
Godwin Chidi Ugwunnadi ${ }^{1,2}$, Lateef Olakunle Jolaoso ${ }^{2,3, *(1)}$ and Chibueze Christian Okeke ${ }^{4}$ \\ 1 Department of Mathematics, University of Eswatini, Private Bag 4, Kwaluseni M201, Eswatini; \\ gcugwunnadi@uniswa.az or ugwunnadi4u@yahoo.com \\ 2 Department of Mathematics and Applied Mathematics, Sefako Makgatho Health Sciences University, \\ P.O. Box 94, Medunsa 0204, South Africa \\ 3 Department of Mathematics, Federal University of Agriculture, Abeokuta 2240, Ogun State, Nigeria \\ 4 School of Mathematics, University of the Witwatersrand, Private Bag 3, Johannesburg 2050, South Africa; \\ chibueze.okeke@wits.ac.za \\ * Correspondence: lateef.jolaoso@smu.ac.za
}

\section{check for}

updates

Citation: Ugwunnadi, G.C.; Jolaoso, L.O.; Okeke, C.C. A Generalized Explicit Iterative Method for Solving Generalized Split Feasibility Problem and Fixed Point Problem in Real Banach Spaces. Symmetry 2022, 14, 335. https:// doi.org/10.3390/sym14020335

Academic Editor: Alexander Zaslavski

Received: 24 August 2021 Accepted: 23 September 2021 Published: 6 February 2022

Publisher's Note: MDPI stays neutral with regard to jurisdictional claims in published maps and institutional affiliations.

Copyright: (c) 2022 by the authors. Licensee MDPI, Basel, Switzerland. This article is an open access article distributed under the terms and conditions of the Creative Commons Attribution (CC BY) license (https:// creativecommons.org/licenses/by/ $4.0 /)$.

\begin{abstract}
In this paper, we propose a generalized explicit algorithm for approximating the common solution of generalized split feasibility problem and the fixed point of demigeneralized mapping in uniformly smooth and 2-uniformly convex real Banach spaces. The generalized split feasibility problem is a general mathematical problem in the sense that it unifies several mathematical models arising in (symmetry and non-symmetry) optimization theory and also finds many applications in applied science. We designed the algorithm in such a way that the convergence analysis does not need a prior estimate of the operator norm. More so, we establish the strong convergence of our algorithm and present some computational examples to illustrate the performance of the proposed method. In addition, we give an application of our result for solving the image restoration problem and compare with other algorithms in the literature. This result improves and generalizes many important related results in the contemporary literature.
\end{abstract}

Keywords: demigeneralized mapping; fixed point; monotone mapping; mid-point method; strong convergence; Banach spaces

MSC: 49J40; 58E35; 65K15; 90C33

\section{Introduction}

Let $C$ and $Q$ be nonempty, closed, and convex subsets of two real Hilbert spaces $H_{1}$ and $H_{2}$, respectively, and $B: H_{1} \rightarrow H_{2}$ be a bounded linear operator. The Split Feasibility Problem (shortly, SFP) is defined as

$$
\text { Find } v^{*} \in C \text { such that } B v^{*} \in Q \text {. }
$$

We denote the set of solutions of the SFP (1) by $\operatorname{SFP}(C, Q, B)$, i.e., $\operatorname{SFP}(C, Q, B)=$ $\left\{v^{*} \in C: B v^{*} \in Q\right\}$. The SFP was first introduced by [1] in the setting of finite dimensional spaces, for modeling inverse problems arising from phrase retrievals and in medical image reconstruction. Since then, it has been studied widely and extended by many researchers mainly due to its applications in various areas such as radiation therapy treatment planning, signal processing, image restoration, computer tomography, etc., see e.g., [2-5].

In 2014, Ref. [6] introduced the Generalized Split Feasibility Problem (GSFP) in the framework of real Hilbert spaces as follows:

$$
\text { Find } v^{*} \in C \text { such that } 0 \in A v^{*} \text { and } B v^{*} \in F(T) \text {, }
$$


where $A: H_{1} \rightarrow 2^{H_{1}}$ is a maximal monotone operator, $B: H_{1} \rightarrow H_{2}$ is a bounded linear operator, $T: \mathrm{H}_{2} \rightarrow \mathrm{H}_{2}$ is a non-expansive mapping and $F(T) \neq \varnothing$ is the set of fixed points of $T$, i.e., $F(T):=\{x \in H: T x=x\}$. We denote the set of solution of the GSFP (2) by $\Omega$. Note that, when $B=N_{C}$ (i.e., the normal cone operator at $C$ ) and $F(T)=Q$, the GSFP reduces to the SFP. Ref. [6] proposed the following iterative method for solving the GSFP in real Hilbert spaces:

$$
x_{n+1}=J_{\lambda_{n}}^{A}\left(I-\gamma B^{*}(I-T) B\right) x_{n} \quad \forall n \in \mathbb{N},
$$

where $J_{\lambda}^{A} x=(I-\lambda A)^{-1} x$ is the resolvent operator of $A$ and $B^{*}: H_{2} \rightarrow H_{1}$ is the adjoint of $B$. They also proved that the sequence $\left\{x_{n}\right\}$ generated by (3) converges weakly to a solution of the GSFP. Recently, Ref. [7] extended the result of [6] to the setting of uniformly convex and 2-uniformly smooth real Banach spaces. They proposed the following iterative method in particular, for solving the GSFP in real Banach spaces:

$$
\left\{\begin{array}{l}
y_{n}=J_{E_{1}}^{-1}\left(J_{E_{1}} x_{n}-\gamma B^{*} J_{E_{2}}(I-U) B x_{n}\right), \\
x_{n+1}=J_{E_{1}}^{-1}\left(\beta_{n} J_{E_{1}} x_{n}+\left(1-\beta_{n}\right) J_{E_{1}} T J_{\lambda}^{A} y_{n}\right), \quad \forall n \in \mathbb{N},
\end{array}\right.
$$

where $0<a \leq \beta_{n} \leq b<1, \gamma \in\left(0, \frac{1}{\|B\|^{2}}\right), \lambda>0, J_{E_{1}}$ and $J_{E_{2}}$ are the normalized duality mapping on the real Banach spaces $E_{1}$ and $E_{2}$, respectively, $A: E_{1} \rightarrow 2^{E_{1}^{*}}$ is a maximal monotone operator and $T: C \rightarrow C$ and $U: E_{2} \rightarrow E_{2}$ are nonexpansive mappings with $F(U) \neq 0$. The authors proved that the sequence generated by (4) converges weakly to an element in $\Gamma=\Omega \cap F(T)$. Furthermore, Ref. [8] also introduced a strong convergence algorithm for finding a common element in the set of solution of GSFP and common fixed point problem for a countable family of nonexpansive mappings between a real Hilbert space $H$ and real Banach space $E$ as follows:

$$
\left\{\begin{array}{l}
x_{1} \in H \\
z_{n}=J_{\lambda_{n}}^{A}\left(x_{n}-\gamma_{n} B^{*} J_{E}\left(B x_{n}-U B x_{n}\right)\right) \\
y_{n}=\left(1-\sigma_{n}\right) z_{n}+\sigma_{n} \sum_{i=1}^{\infty} \eta_{i} T_{i} z_{n} \\
x_{n+1}=P_{C}\left(\alpha_{n} x_{0}+\beta_{n} y_{n}+\delta_{n} z_{n}\right),
\end{array}\right.
$$

where $P_{C}$ is the metric projection from $H$ onto $C, J_{E}: E \rightarrow 2^{E}$ is the normalized duality mapping on $E, B: H \rightarrow E$ is a bounded linear operator, $U: E \rightarrow E$ is a firmly nonexpansivelike mapping, $T_{i}$ is a countable family of demimetric mappings on $C$ with $k_{i} \in(-\infty, 1)$, $\left\{\alpha_{n}\right\},\left\{\beta_{n}\right\},\left\{\delta_{n}\right\},\left\{\eta_{i}\right\} \subset(0,1),\left\{\lambda_{n}\right\},\left\{\sigma_{n}\right\},\left\{\gamma_{n}\right\} \subset(0,+\infty)$ are sequences satisfying the following conditions:

(i) $\lim _{n \rightarrow \infty} \alpha_{n}=0$, and $\sum_{n=0}^{\infty} \alpha=\infty$,

(ii) $0<\liminf _{n \rightarrow \infty} \beta_{n} \leq \limsup \sup _{n \rightarrow \infty} \beta_{n}<1$ and $\alpha_{n}+\beta_{n}+\delta_{n}=1$,

(iii) $\sum_{i=1}^{\infty} \eta_{i}=1$,

(iv) $0<a \leq \gamma_{n} \leq b$ and $1-k$, where $k=\sup \left\{k_{i}, i \in \mathbb{N}\right\}<1$,

(v) $0<c \leq \gamma_{n} \leq \gamma<\frac{2}{\|B\|^{2}}$ and $0<\liminf _{n \rightarrow \infty} \lambda_{n} \leq \lim \sup _{n \rightarrow \infty} \lambda_{n}<\infty$.

Very recently, Ref. [9] further introduced a Halpern-type strong convergence algorithm for solving the GSFP in real Banach spaces as follows:

$$
\left\{\begin{array}{l}
x_{1}, u \in E_{1}, \\
y_{n}=J_{E_{1}}^{-1}\left(J_{E_{1}} x_{n}-\gamma B^{*} J_{E_{2}}(I-U) B x_{n}\right), \\
x_{n+1}=J_{E_{1}}^{-1}\left(\alpha_{n} J_{E_{1}} u+\left(1-\alpha_{n}\right) J_{E_{1}} Q_{r_{n}}^{A} T y_{n}\right), \quad \forall n \in \mathbb{N},
\end{array}\right.
$$

where $\left\{\alpha_{n}\right\} \subset(0,1)$ satisfying $\lim _{n \rightarrow \infty} \alpha_{n}=0, \sum_{n=0}^{\infty} \alpha_{n}=+\infty$ and $0<\gamma<\frac{1-\tau}{\|B\|^{2}}, T$ : $E_{2} \rightarrow E_{2}$ is a $\tau$-quasi-strictly pseudononspreading mappings such that $F(T) \neq \varnothing$. The authors proved that the sequence $\left\{x_{n}\right\}$ generated by Algorithm (6) converges strongly to 
an element in $\Omega$ under some mild conditions on the control sequences. Note that, in the methods mentioned above, the stepsize $\gamma_{n}$ depends on prior estimates of the norm of the bounded linear operator, i.e., $\|B\|$, which, in general, it is very difficult to estimate (see, e.g., [10]), thus the following question arises naturally:

Question A: Can we provide an iterative scheme which does not depend on a prior estimate of the norm of the bounded linear operator for solving the generalized split feasibility problem in real Banach spaces?

On the other hand, Ref. [11] introduced the generalized viscosity implicit rule for approximating the fixed point of a nonexpansive mapping $T: C \rightarrow C$ in real Hilbert spaces as follows: given $x_{0} \in C$, compute

$$
x_{n+1}=\alpha_{n} f\left(x_{n}\right)+\left(1-\alpha_{n}\right) T\left(t_{n} x_{n}+\left(1-t_{n}\right) x_{n+1}\right) \quad \forall n \geq 0 .
$$

They also proved that the sequence $\left\{x_{n}\right\}$ generated by (7) converges strongly to a point in $F(T)$. However, it was noted that the computation by implicit method is not a simple task in general. To overcome this difficulty, the explicit midpoint method was given by the following finite difference scheme which was originally introduced in the books [12,13]:

$$
\left\{\begin{array}{l}
y_{0}=x_{0}, \\
\bar{y}_{n+1}=y_{n}+h f\left(y_{n}\right), \\
y_{n+1}=y_{n}+h f\left(\frac{y_{n}+\bar{y}_{n+1}}{2}\right) \forall n \geq 0,
\end{array}\right.
$$

where $f: H \rightarrow H$ is a contraction mapping and $h \in[0,1]$ is the mesh. In 2017, Ref. [14] combined the generalized viscosity implicit midpoint method (7) with the explicit midpoint method (8) for approximating the fixed point problem of a quasi-nonexpansive mapping $T$. They introduced the following generalized viscosity explicit midpoint method in particular: for any $x_{1} \in C$ and

$$
\left\{\begin{array}{l}
\bar{x}_{n+1}=\beta_{n} x_{n}+\left(1-\beta_{n}\right) T x_{n} \\
x_{n+1}=\alpha_{n} f\left(x_{n}\right)+\left(1-\alpha_{n}\right) T\left(t_{n} x_{n}+\left(1-t_{n}\right) \bar{x}_{n+1}\right) \forall n \geq 1
\end{array}\right.
$$

They also showed that the sequence $\left\{x_{n}\right\}$ generated by (9) converges strongly to a fixed point of $T$ under certain assumptions imposed on the parameters $\left\{\alpha_{n}\right\},\left\{\beta_{n}\right\}$, and $\left\{t_{n}\right\}$.

Motivated by the above results, in this paper, we provide an affirmative answer to Question A using the technique above in real Banach spaces. In particular, we introduce a generalized explicit method for solving the GSFP without prior knowledge of the norm of the bounded operator in uniformly smooth and 2-uniformly convex real Banach spaces. The algorithm is designed such that its stepsize is determined self-adaptively at each iteration, and its convergence does not require prior estimate of the bounded linear operator norm. We also prove a strong convergence result for the sequence generated by the algorithm and also provide a numerical example to illustrate the performance of the iterative method. Furthermore, we utilize the algorithm to solves image restoration problem and also compare it performance with other related methods in the literature.

\section{Preliminaries}

In this section, we present some preliminary Definitions and concepts which are needed in this paper. Let $E$ be a real Banach space with dual $E^{*}$ and $S_{E}(x):=\{x \in E$ : $\|x\|=1\}$ denotes the unit sphere of $E$. We denote the value of $y \in E^{*}$ at $x \in E$ by $\langle x, y\rangle$. In addition, we denote the strong (resp. weak) convergence of a sequence $\left\{x_{n}\right\} \subset E$ to a point $x \in E$ by $x_{n} \rightarrow x$ (resp. $x_{n} \rightarrow x$ ).

Let $E_{1}, E_{2}$ be two Banach spaces and $B: E_{1} \rightarrow E_{2}$ denotes the bounded linear operator. Then, the adjoint operator of $B$ which is denoted by $B^{*}$ is defined as $B^{*}: E_{2}^{*} \rightarrow E_{1}^{*}$ with 
$\left\langle x, B^{*} y\right\rangle=\langle B x, y\rangle$ for all $x \in E_{1}$ and $y \in E_{2}^{*} . B^{*}$ is also bounded linear operator and $\|B\|=\left\|B^{*}\right\|$.

A Banach space $E$ is said to be smooth if $\lim _{t \rightarrow 0} \frac{\|x+t y\|-\|x\|}{t}$ exists for each $x, y \in S_{E}$ and for any $\lambda \in(0,1)$, if $\|\lambda x+(1-\lambda) y\|<1$ for all $x, y \in S_{E}$ with $x \neq y$, then $E$ is called strictly convex. In addition, $E$ is said to be uniformly convex if, for any $\epsilon \in(0,2]$, there exists $\delta=\delta(\epsilon)>0$ such that, if $\frac{\|x+y\|}{2} \leq 1-\delta$, then $\|x-y\| \geq \epsilon$ for all $x, y \in S_{E}$. The modulus of smoothness of $E$ is the function $\rho_{E}:[0, \infty) \rightarrow[0, \infty)$ defined by

$$
\rho_{E}(\tau)=\sup \left\{\frac{\|x+\tau y\|+\|x-\tau y\|}{2}-1: x, y \in S_{E}\right\}
$$

In addition, $E$ is called uniformly smooth if $\lim _{\tau \rightarrow 0} \frac{\rho_{E}(\tau)}{\tau}=0$; q-uniformly smooth if there exists a positive real number $C_{q}$ such that $\rho_{E}(\tau) \leq C_{q} \tau^{q}$ for any $\tau>0$. Hence, every $q$-uniformly smooth Banach space is uniformly smooth. We know that $L_{p}, \ell_{p}$ and $W_{p}^{m}$ are $q$-uniformly smooth for $1 \leq q<2$; 2-uniformly smooth and uniformly convex (see [15] for more details).

Furthermore, the normalized duality mapping $J: E \rightarrow 2^{E^{*}}$ is defined by

$$
J(x):=\left\{y \in E^{*}:\langle x, y\rangle=\|y\|^{2}=\|x\|^{2}\right\}, \quad y \in E .
$$

It is known that $J$ has the following properties (for more details, see [16-18]):

(UM1) If $E$ is smooth, then $J$ is single-valued.

(UM2) If $E$ is strictly convex, then $J$ is one to one and strictly monotone.

(UM3) If $E$ is uniformly smooth, then $J$ is uniformly norm to norm continuous on a bounded subset of $E$.

(UM4) If $E$ is smooth, strictly convex, and reflexive Banach space, then $J$ is single-valued, one to one and onto.

(UM5) If $E$ is uniformly smooth and uniformly convex, then the dual space $E^{*}$ is also uniformly smooth and uniformly convex; furthermore, $J$ and $J^{-1}$ are both uniformly continuous on bounded subsets of $E$.

(UM6) If $E$ is a reflexive, strictly convex, and smooth Banach space, then $J^{-1}$ (the duality mapping from $E^{*}$ into $E$ ) is single-valued, one to one and onto.

Let $E$ be a Banach space and $\phi: E \times E \rightarrow[0, \infty)$ denotes the Lyapunov functional defined as

$$
\phi(x, y)=\|x\|^{2}-2\langle x, J y\rangle+\|y\|^{2}, \forall x, y \in E .
$$

The functional $\phi$ satisfies the following properties (see [19]):

(A1) $(\|x\|-\|y\|)^{2} \leq \phi(x, y) \leq(\|x\|+\|y\|)^{2}, \quad \forall x, y \in E$;

(A2) $\phi(x, y)=\phi(x, z)+\phi(z, y)+2\langle x-z, J z-J y\rangle, \quad \forall x, y, z \in E$;

(A3) $\phi(x, y)=\langle x, J x-J y\rangle+\langle y-x, J y\rangle \leq\|x\|\|J x-J y\|+\|y-x\|\|y\|, \quad x, y \in E$;

(A4) $\phi\left(z, J^{-1}(\alpha J x+(1-\alpha) J y)\right) \leq \alpha \phi(z, x)+(1-\alpha) \phi(z, y)$, where $\alpha \in(0,1)$ and $x, y \in E$.

Remark 1. If $E$ is strictly convex, then, for all $x, y \in E, \phi(x, y)=0$ if and only if $x=y$ (See Remark 2.1 in [20]).

Now, we introduce another functional-like $V: E \times E^{*} \rightarrow[0, \infty)$ by [21], which is a mild modification and has a relationship with a Lyapunov functional as follows:

$$
V\left(x, x^{*}\right)=\|x\|^{2}-2\left\langle x, x^{*}\right\rangle+\left\|x^{*}\right\|^{2}
$$

for all $x \in E$ and $x^{*} \in E^{*}$. From the Definition of $\phi$, we get

$$
V\left(x, x^{*}\right)=\phi\left(x, J^{-1}\left(x^{*}\right)\right), \text { for all } x \in E \text { and } x^{*} \in E^{*} .
$$


For each $x \in E$, the mapping $g$ defined by $g\left(x^{*}\right)=V\left(x, x^{*}\right)$ for all $x^{*} \in E^{*}$ is a continuous, convex function from $E^{*}$ into $\mathbb{R}$. The following Lemma is a very important property of $V$.

Lemma 1 ([21]). Let E be a reflexive, strictly convex and smooth Banach space and let $V$ be as in (10). Then,

$$
V\left(x, x^{*}\right)+2\left\langle J^{-1} x^{*}-x, y^{*}\right\rangle \leq V\left(x, x^{*}+y^{*}\right)
$$

for all $x \in E$ and $x^{*}, y^{*} \in E^{*}$.

Let $E$ a be reflexive, strictly convex and smooth Banach space and $C$ a nonempty closed and convex subset of $E$. Then, by [21], for each $x \in E$, there exists a unique element $u \in C$ (denoted by $\left.\Pi_{C} x\right)$ such that

$$
\phi(u, x)=\min _{y \in C} \phi(y, x) .
$$

The mapping $\Pi_{C}: E \rightarrow C$, defined by $\Pi_{C} x=u$, is called the generalized projection operator (see [22]), which has the following important characteristic.

Lemma 2 ([23]). Let $C$ be a nonempty, closed and convex subset of a smooth Banach space E, if $u \in E$. Then, $v=\Pi_{C} x$ if and only if

$$
\langle v-w, J u-J v\rangle \geq 0, \quad \forall w \in C .
$$

In the sequel, we shall use the following results.

Lemma 3 ([19]). Let $E$ be a uniformly smooth Banach space and $r>0$. Then, there exists a continuous, strictly increasing and convex function $g:[0,2 r] \rightarrow[0, \infty]$ such that $g(0)=0$ and

$$
\phi\left(u, J^{-1}(t J v+(1-t) J w)\right) \leq t \phi(u, v)+(1-t) \phi(u, w)-t(1-t) g(\|J v-J w\|)
$$

for all $t \in[0,1], u \in E$ and $v, w \in B_{r}:=\{z \in E:\|z\| \leq r\}$.

Lemma 4 ([15]). Let E be a real uniformly convex Banach space and $r>0$. Let $B_{r}(0):=\{x \in$ $E:\|x\| \leq r\}$. Then, there exists a continuous strictly increasing convex function $g:[0,2 r] \rightarrow \mathbb{R}$, such that $g(0)=0$ and

$$
\|\beta y+(1-\beta) z\|^{2} \leq \beta\|y\|^{2}+(1-\beta)\|y\|^{2}-\beta(1-\beta) g(\|y-z\|),
$$

for all $y, z \in B_{r}$ and $\beta \in[0,1]$.

Lemma 5 ([20]). Let E be a uniformly convex and smooth Banach space and $\left\{u_{n}\right\}$ and $\left\{v_{n}\right\}$ be two sequences in $E$. If $\lim _{n \rightarrow \infty} \phi\left(u_{n}, v_{n}\right)=0$ and either $\left\{u_{n}\right\}$ or $\left\{v_{n}\right\}$ is bounded, then $\lim _{n \rightarrow \infty}\left\|u_{n}-v_{n}\right\|=0$.

Lemma 6 ([15]). Let E be a 2-uniformly convex and smooth real Banach space. Then, there exists a positive real-valued constant $\alpha$ such that

$$
\alpha\|x-y\|^{2} \leq \phi(x, y), \quad \forall x, y \in E .
$$

Lemma 7 ([15]). Let E be a 2-uniformly smooth Banach space, then, for each $s>0$ and $x, y \in E$, the following holds:

$$
\|x+y\|^{2} \leq\|x\|^{2}+2\langle x, J y\rangle+2 s^{2}\|y\|^{2} .
$$

Definition 1. A mapping $T: C \rightarrow E$ is said to be: 
(i) quasi-nonexpansive (see [20]) if $F(T) \neq \varnothing$ and

$$
\phi(p, T x) \leq \phi(p, x), \quad \forall x \in C, p \in F(T),
$$

(ii) firmly nonexpansive type if for all $x, y \in C$, we have

$$
\phi(T x, T y)+\phi(T y, T x)+\phi(T x, x)+\phi(T y, y) \leq \phi(T x, y)+\phi(T y, x) .
$$

(iii) quasi- $\phi$-strictly pseudocontractive (see [24]) if $F(T) \neq \varnothing$ and there exists a constant $k \in[0,1)$ such that

$$
\phi(p, T x) \leq \phi(p, x)+k \phi(x, T x), \quad \forall x \in C \text { and } p \in F(T) .
$$

(iv) $(\eta, s)$-demigeneralized (see [25]) if $F(T) \neq \varnothing$ and there exists $\eta \in(-\infty, 1)$ and $s \in[0, \infty)$ such that for any $x \in C$ and $q \in F(T)$, we have

$$
2\langle x-q, J x-J T x\rangle \geq(1-\eta) \phi(x, T x)+s \phi(T x, x) .
$$

In particular, $T$ is $(\eta, 0)$-demigeneralized mapping if and only if

$$
2\langle x-q, J x-J T x\rangle \geq(1-\eta) \phi(x, T x) .
$$

A set-valued operator $A: C \rightarrow 2^{E^{*}}$ is said to be: (i) monotone if for all $x, y \in C$, we have

$$
\langle x-y, u-v\rangle \geq 0
$$

where $u \in A x$ and $v \in A y$, (ii) maximal monotone if $A$ is monotone and the graph of $A$ i.e., $G(A):=\left\{(x, y) \in E \times E^{*}: y \in A(x)\right\}$ is not properly contained in the graph of any other monotone operator. It is known that, when $A$ is a maximal monotone operator and $r>0$, then the resolvent of $A$ is defined by $Q_{r} x=(J+r A)^{-1} J x$ for $x \in E$. More so, the null points of $A$ is defined by $A^{-1}(0):=\{w \in E: 0 \in A w\}$. Note that $A^{-1}(0)$ is a closed and convex set, and $F\left(Q_{r}\right)=A^{-1}(0)$, (see [18]).

Lemma 8 ([26,27]). Let $C$ be a nonempty, closed and convex subset of strictly convex, smooth and reflexive Banach space, and let $r>0$ and $A \subset E \times E^{*}$ be a monotone operator such that $D(A) \subset J^{-1} R(J+r A)$. Then, the resolvent of $A$ which is defined by $Q_{r} x=(J+r A)^{-1} J x$ for all $x \in C$ is a firmly nonexpansive type mapping.

Lemma 9 ([28]). Let $E$ be a reflexive, smooth and strictly convex Banach space and $A: E \rightarrow 2^{E^{*}}$ a maximal monotone operator such that $A^{-1}(0) \neq \varnothing$ and $Q_{r}=(J+\mu A)^{-1} J$ for all $r>0$. Then,

$$
\phi\left(u, Q_{r} v\right)+\phi\left(Q_{r} v, v\right) \leq \phi(u, v) \forall u \in F\left(Q_{r}\right), v \in E
$$

Lemma 10 ([25]). Let $E$ be a smooth Banach space and $C$ be a nonempty closed and convex subset of $E$. Let $\eta$ be a real number with $\eta \in(-\infty, 1)$ and s be a real number with $s \in[0, \infty)$. Let $U$ be an $(\eta, s)$-demigeneralized mapping of $C$ into $E$. Then, $F(U)$ is closed and convex.

Lemma 11 ([29]). Let $E$ be a smooth Banach space and $C$ a nonempty closed and convex subset of E. Let $k \in(-\infty, 0]$ and $T: C \rightarrow E$ be $a(k, 0)$-demigeneralized mapping with $F(T) \neq \varnothing$. Let $\lambda$ be a real number in $(0,1]$ and define $T_{\lambda}=J^{-1}((1-\lambda) J+\lambda J T)$, where $J$ is the duality mapping on E. Then, $T_{\lambda}$ is a quasi-nonexpansive mapping of $C$ into $E$ and $F(T)=F\left(T_{\lambda}\right)$. 
Lemma 12 ([30]). If $\left\{a_{n}\right\}$ is a sequence of nonnegative real numbers satisfying the following inequality:

$$
a_{n+1} \leq\left(1-\alpha_{n}\right) a_{n}+\alpha_{n} \sigma_{n}+\gamma_{n}, n \geq 0,
$$

where (i) $\left\{\alpha_{n}\right\} \subset[0,1], \sum \alpha_{n}=\infty$; (ii) $\lim \sup \sigma_{n} \leq 0$; (iii) $\gamma_{n} \geq 0$; $(n \geq 0)$ and $\sum \gamma_{n}<\infty$. Then, $a_{n} \rightarrow 0$ as $n \rightarrow \infty$.

Definition 2. A self-mapping $T$ on a Banach space is said to be demiclosed at $y$, if for any sequence $\left\{x_{n}\right\}$ which converges weakly to $x$, and if the sequence $\left\{T x_{n}\right\}$ converges strongly to $y$, then $T(x)=y$. In particular, if $y=0$, then $T$ is demiclosed at 0 .

Lemma 13 ([31]). Let $\left\{a_{n}\right\}$ be a sequence of real numbers such that there exists a subsequence $\left\{a_{n_{i}}\right\}$ of $\left\{a_{n}\right\}$ such that $a_{n_{i}}<a_{n_{i}+1}$ for all $i \in \mathbb{N}$. Then, there exists a nondecreasing sequence $\left\{m_{k}\right\} \subset \mathbb{N}$ such that $m_{k} \rightarrow \infty$ and the following properties are satisfied by all (sufficiently large) numbers $k \in \mathbb{N}$ :

$$
\begin{gathered}
a_{m_{k}} \leq a_{m_{k}+1} \text { and } a_{k} \leq a_{m_{k}+1} . \\
\text { In fact, } m_{k}=\max \left\{j \leq k: a_{j}<a_{j+1}\right\} .
\end{gathered}
$$

\section{Results}

In this section, we present our algorithm and its convergence analysis as follows:

Theorem 1. Let $E_{1}$ and $E_{2}$ be uniformly smooth and 2-uniformly convex real Banach spaces. Let $T: E_{1} \rightarrow E_{1}$ be a $(\eta, 0)$-demigeneralized mapping and demiclosed at zero with $\eta \in(-\infty, \lambda]$ and $\lambda \in[0,1)$ such that $F(T) \neq \varnothing$. Let $U: E_{2} \rightarrow E_{2}$ be a $(\theta, 0)$-demigeneralized mapping and demiclosed at zero with $\theta \in(-\infty, 0]$ such that $F(U) \neq \varnothing$. Let $A$ be a maximal monotone operator of $E$ into $2^{E^{*}}$ such that $A^{-1} \neq \varnothing$ and $Q_{\mu}$ are the generalized resolvent operator of $A$ for $\mu>0$. Let $B: E_{1} \rightarrow E_{2}$ be a bijective bounded linear operator with its adjoint $B^{*}: E_{2}^{*} \rightarrow E_{1}^{*}$. Suppose that $\Gamma:=F(T) \cap A^{-1}(0) \cap B^{-1}(F(U)) \neq \varnothing$. Let $\left\{u_{n}\right\}$ be a sequence in $E_{1}$ such that $u_{n} \rightarrow u \in E_{1}$ and $\left\{x_{n}\right\} \subset E_{1}$ be a sequence generated by the following iterative scheme: given $x_{1} \in E_{1}$, compute

$$
\left\{\begin{array}{l}
w_{n}=J_{E_{1}}^{-1}\left(J x_{n}-\gamma_{n} B^{*}\left(J_{E_{2}}\left(B x_{n}\right)-J_{E_{2}} U\left(B x_{n}\right)\right)\right), \\
\bar{x}_{n+1}=J_{E_{1}}^{-1}\left(\beta_{n} J_{E_{1}}\left(w_{n}\right)+\left(1-\beta_{n}\right) J_{E_{1}} T_{\lambda} Q_{\mu_{n}}\left(w_{n}\right)\right), \\
y_{n}=J_{E_{1}}^{-1}\left(t_{n} J_{E_{1}}\left(x_{n}\right)+\left(1-t_{n}\right) J_{E_{1}} \bar{x}_{n+1}\right), \\
x_{n+1}=J_{E_{1}}^{-1}\left[\alpha_{n} J_{E_{1}}\left(u_{n}\right)+\left(1-\alpha_{n}\right) J_{E_{1}} Q_{\mu_{n}} y_{n}\right], n \geq 1
\end{array}\right.
$$

where $T_{\lambda}:=J_{E_{1}}^{-1}\left((1-\lambda) J_{E_{1}}+\lambda J_{E_{1}} T\right)$ and $\left\{\alpha_{n}\right\},\left\{\beta_{n}\right\},\left\{t_{n}\right\}$ are sequences in $(0,1)$ and $\mu_{n} \subset(0, \infty)$. Suppose the following conditions are satisfied:

(C1) $\lim _{n \rightarrow \infty} \alpha_{n}=0$ and $\sum_{n=1}^{\infty} \alpha_{n}=\infty$;

(C2) for any $\alpha>0$ as in Lemma 6 and any fixed value $a>0$, the stepsize $\gamma_{n}$ is chosen as follows:

$$
0<a \leq \gamma_{n} \leq \frac{\alpha(1-\theta)\left\|B x_{n}-U B x_{n}\right\|^{2}}{s^{2}\left\|B^{*}\left(J_{E_{2}}\left(B x_{n}\right)-J_{E_{2}}\left(U B x_{n}\right)\right)\right\|^{2}}-a,
$$

if $B x_{n} \neq U B x_{n}$; otherwise, $\gamma_{n}=\gamma(\gamma \geq 0)$.

(C3) $0<t \leq t_{n} \leq t^{*}<1$ and $0<\beta \leq \beta_{n} \leq \beta^{*}<1$, where $\left[t, t^{*}\right] \subset(0,1),\left[\beta, \beta^{*}\right] \subset(0,1)$.

Then, $\left\{x_{n}\right\}_{n=1}^{\infty}$ converges strongly to $z^{*} \in \Gamma$, where $z^{*}=\Pi_{\Gamma} u$.

Remark 2. Since $T: E_{1} \rightarrow E_{1}$ and $U: E_{2} \rightarrow E_{2}$ are $(\eta, 0)$ and $(\theta, 0)$-demigeneralized mappings, respectively, then $F(T)$ and $F(U)$ are closed and convex sets by Lemma 10. Since $B: E_{1} \rightarrow E_{2}$ is linear and bounded and $B^{-1}$ exists, then $B^{-1}$ is linear and bounded (continuous). Since $F(U)$ is closed and convex, then $B^{-1}(F(U))$ is also closed and convex. $A^{-1}(0)$ is closed and convex (see [18] for details). Hence, $\Gamma:=F(T) \cap A^{-1}(0) \cap B^{-1}(F(U))$ is nonempty closed and convex. Therefore, $\Pi_{\Gamma}$ from $E_{1}$ into $\Gamma$ is well-defined. 
Furthermore, since $T_{\lambda}:=J_{E_{1}}^{-1}\left((1-\lambda) J_{E_{1}}+\lambda J_{E_{1}} T\right)$ for any $\lambda \in[0,1)$ is relatively nonexpansive mapping and $F(T)=F\left(T_{\lambda}\right)$ by Lemma 11. Let $z \in \Gamma$, we have that $z \in F(T)=F\left(T_{\lambda}\right)$, $z \in B^{-1}(F(U)) \Rightarrow B z=U B z$, thus $(B z-U B z)=0$, and also $z=Q_{\mu_{n}} z$. In addition, since $Q_{\mu_{n}}$ is generalized resolvent for $\mu_{n}>0$, then, from Lemma 8, we have that $Q_{\mu_{n}}$ is firmly nonexpansive operator for $z \in F\left(Q_{\mu_{n}}\right)$, then for any $x_{n} \in E_{1}$, we have $\phi\left(z, Q_{\mu_{n}} x_{n}\right) \leq \phi\left(z, x_{n}\right)$ for all $n \geq 1$.

Proof. Let $z \in \Gamma$, then, from Lemma 6, 7 and (15), we have

$$
\begin{aligned}
\phi\left(z, w_{n}\right)= & \phi\left(z, J_{E_{1}}^{-1}\left(J_{E_{1}} x_{n}-\gamma_{n} B^{*}\left(J_{E_{2}}\left(B x_{n}\right)-J_{E_{2}} U\left(B x_{n}\right)\right)\right)\right) \\
= & V\left(z, J_{E_{1}} x_{n}-\gamma_{n} B^{*}\left(J_{E_{2}}\left(B x_{n}\right)-J_{E_{2}} U\left(B x_{n}\right)\right)\right) \\
= & \|z\|^{2}-2\left\langle z,\left(J_{E_{1}} x_{n}-\gamma_{n} B^{*}\left(J_{E_{2}}\left(B x_{n}\right)-J_{E_{2}} U\left(B x_{n}\right)\right)\right)\right\rangle \\
& +\left\|J x_{n}-\gamma_{n} B^{*}\left(J_{E_{2}}\left(B x_{n}\right)-J_{E_{2}} U\left(B x_{n}\right)\right)\right\|^{2} \\
\leq & \|z\|^{2}-2\left\langle z, J_{E_{1}} x_{n}\right\rangle+2 \gamma_{n}\left\langle z, B^{*}\left(J_{E_{2}}\left(B x_{n}\right)\right)-J_{E_{2}}\left(U B x_{n}\right)\right\rangle \\
& +\left\|J_{E_{1}}\left(x_{n}\right)\right\|^{2}-2 \gamma_{n}\left\langle x_{n}, B^{*}\left(J_{E_{2}}\left(B x_{n}\right)\right)-J_{E_{2}}\left(U B x_{n}\right)\right. \\
& +\gamma_{n}^{2} s^{2}\left\|B^{*}\left(J_{E_{2}}\left(B x_{n}\right)\right)-J_{E_{2}}\left(U B x_{n}\right)\right\|^{2} \\
= & \phi\left(z, x_{n}\right)-2 \gamma_{n}\left\langle B\left(x_{n}\right)-B(z),\left(J_{E_{2}}\left(B x_{n}\right)\right)-J_{E_{2}}\left(U B x_{n}\right)\right\rangle \\
& +\gamma_{n}^{2} s^{2}\left\|B^{*}\left(J_{E_{2}}\left(B x_{n}\right)\right)-J_{E_{2}}\left(U B x_{n}\right)\right\|^{2} \\
\leq & \phi\left(z, x_{n}\right)-\gamma_{n}(1-\eta) \phi\left(B x_{n}, U\left(B x_{n}\right)\right) \\
& +\gamma_{n}^{2} s^{2}\left\|B^{*}\left(J_{E_{2}}\left(B x_{n}\right)\right)-J_{E_{2}}\left(U B x_{n}\right)\right\|^{2} \\
\leq & \phi\left(z, x_{n}\right)-\gamma_{n} \alpha(1-\eta) \| B x_{n}-U\left(B x_{n} \|^{2}\right. \\
& +\gamma_{n}^{2} s^{2}\left\|B^{*}\left(J_{E_{2}}\left(B x_{n}\right)\right)-J_{E_{2}}\left(U B x_{n}\right)\right\|^{2} \\
= & \phi\left(z, x_{n}\right)-\gamma_{n}\left(\alpha(1-\eta)\left\|\left(B x_{n}\right)-U\left(B x_{n}\right)\right\|^{2}\right. \\
& \left.-\gamma_{n} s^{2}\left\|B^{*}\left(J_{E_{2}}\left(B x_{n}\right)\right)-J_{E_{2}}\left(U B x_{n}\right)\right\|^{2}\right) \\
\leq & \phi\left(z, x_{n}\right),
\end{aligned}
$$

where the last estimation follows from the stepsize rule (18). In addition, from $\left(y_{n}\right)$ in (17) and (24), we have

$$
\begin{aligned}
\phi\left(z, y_{n}\right) & =\phi\left(z, J_{E_{1}}^{-1}\left(t_{n} J_{E_{1}}\left(x_{n}\right)+\left(1-t_{n}\right) J_{E_{1}} \bar{x}_{n+1}\right)\right) \\
& \leq t_{n} \phi\left(z, x_{n}\right)+\left(1-t_{n}\right) \phi\left(z, \bar{x}_{n+1}\right) \\
& =t_{n} \phi\left(z, x_{n}\right)+\left(1-t_{n}\right) \phi\left(z, J_{E_{1}}^{-1}\left(\beta_{n} J_{E_{1}} w_{n}+\left(1-\beta_{n}\right) J_{E_{1}} T_{\lambda} Q_{\mu_{n}} w_{n}\right)\right) \\
& \leq t_{n} \phi\left(z, x_{n}\right)+\left(1-t_{n}\right)\left[\beta_{n} \phi\left(z, w_{n}\right)+\left(1-\beta_{n}\right) \phi\left(z, Q_{\mu_{n}} w_{n}\right)\right] \\
& =t_{n} \phi\left(z, x_{n}\right)+\left(1-t_{n}\right) \phi\left(z, w_{n}\right) \\
& \leq \phi\left(z, x_{n}\right)
\end{aligned}
$$

and

$$
\begin{aligned}
\phi\left(z, x_{n+1}\right) & =\phi\left(z, J_{E_{1}}^{-1}\left(\alpha_{n} J_{E_{1}} u_{n}+\left(1-\alpha_{n}\right) J_{E_{1}} Q_{\mu_{n}} y_{n}\right)\right) \\
& \leq \alpha_{n} \phi\left(z, u_{n}\right)+\left(1-\alpha_{n}\right) \phi\left(z, y_{n}\right) \\
& \leq \alpha_{n} \phi\left(z, u_{n}\right)+\left(1-\alpha_{n}\right) \phi\left(z, x_{n}\right) .
\end{aligned}
$$

Since $\left\{u_{n}\right\}$ converges, then it is bounded and so, with the help of (A1), there exists $M>0$, such that $\sup \phi\left(z, u_{n}\right) \leq M$. Now, letting $M^{*}=\max \left\{M, \phi\left(z, x_{n}\right)\right\}$, for all $n \geq 1$, in particular, $\phi\left(z, x_{1}\right) \leq M^{*}$. Assuming for some $k \geq 1$ that $\phi\left(z, x_{k}\right) \leq M^{*}$, then, by (24), we have

$$
\begin{aligned}
\phi\left(z, x_{k+1}\right) & \leq \alpha_{k} \phi\left(z, u_{k}\right)+\left(1-\alpha_{k}\right) \phi\left(z, x_{k}\right) \\
& \leq \alpha_{k} M^{*}+\left(1-\alpha_{k}\right) M^{*}=M^{*} .
\end{aligned}
$$


Hence by induction, we obtain that $\phi\left(z, x_{n}\right) \leq M^{*}$ for all $n \in \mathbb{N}$. Therefore, $\left\{x_{n}\right\}_{n=1}^{\infty}$ is bounded.

Furthermore, from (19), (21) and (23), we get

$$
\begin{aligned}
\phi\left(z, x_{n+1}\right) \leq & \alpha_{n} \phi\left(z, u_{n}\right)+\left(1-\alpha_{n}\right)\left[t_{n} \phi\left(z, x_{n}\right)+\left(1-t_{n}\right) \phi\left(z, w_{n}\right)\right] \\
\leq & \alpha_{n} \phi\left(z, u_{n}\right)+t_{n} \phi\left(z, x_{n}\right)+\left(1-t_{n}\right) \phi\left(z, w_{n}\right) \\
\leq & \alpha_{n} \phi\left(z, u_{n}\right)+\phi\left(z, x_{n}\right)-\gamma_{n}\left(1-t_{n}\right)\left(\alpha(1-\eta)\left\|\left(B x_{n}\right)-U\left(B x_{n}\right)\right\|^{2}\right. \\
& \left.-\gamma_{n} s^{2}\left\|B^{*}\left(J_{E_{2}}\left(B x_{n}\right)\right)-J_{E_{2}}\left(U B x_{n}\right)\right\|^{2}\right) .
\end{aligned}
$$

From (C2), we have that $\gamma_{n} \leq \frac{\alpha(1-\eta)\left\|B x_{n}-U\left(B x_{n}\right)\right\|^{2}}{s^{2}\left\|B^{*}\left(J_{E_{2}}\left(B x_{n}\right)-J_{E_{2}} U\left(B x_{n}\right)\right)\right\|^{2}}-a$, hence

$$
\begin{aligned}
\gamma_{n} s^{2}\left\|B^{*}\left(J_{E_{2}}\left(B x_{n}\right)-J_{E_{2}} U\left(B x_{n}\right)\right)\right\|^{2} \leq & \alpha(1-\eta)\left\|\left(B x_{n}\right)-U\left(B x_{n}\right)\right\|^{2} \\
& -a s^{2}\left\|B^{*}\left(J_{E_{2}}\left(B x_{n}\right)-J_{E_{2}} U\left(B x_{n}\right)\right)\right\|^{2} .
\end{aligned}
$$

This implies that

$$
\begin{aligned}
a s^{2}\left\|B^{*}\left(J_{E_{2}}\left(B x_{n}\right)-J_{E_{2}} U\left(B x_{n}\right)\right)\right\|^{2} \leq & \alpha(1-\eta)\left\|\left(B x_{n}\right)-U\left(B x_{n}\right)\right\|^{2} \\
& -\gamma_{n} s^{2}\left\|B^{*}\left(J_{E_{2}}\left(B x_{n}\right)-J_{E_{2}} U\left(B x_{n}\right)\right)\right\|^{2} .
\end{aligned}
$$

Hence, from (25) and (26), we get

$$
\begin{aligned}
\gamma_{n} a^{2} s^{2}\left(1-t_{n}\right)\left\|B^{*}\left(J_{E_{2}}\left(B x_{n}\right)-J_{E_{2}}\left(U\left(B x_{n}\right)\right)\right)\right\|^{2} \leq & \alpha_{n} \phi\left(z, u_{n}\right) \\
& +\phi\left(z, x_{n}\right)-\phi\left(z, x_{n+1}\right) .
\end{aligned}
$$

The remaining part of the proof will be divided into two cases.

Case I: Suppose that the sequence $\left\{\phi\left(z, x_{n}\right)\right\}_{n=1}^{\infty}$ is non-increasing sequence of real numbers. Since this sequence $\left\{\phi\left(z, x_{n}\right)\right\}_{n=1}^{\infty}$ is bounded, then it converges for all $n \geq n_{0}$. That is,

$$
\lim _{n \rightarrow \infty}\left(\phi\left(z, x_{n}\right)-\phi\left(z, x_{n+1}\right)\right)=0 .
$$

Thus, from (C1), (C3), (27) and (28), we have

$$
\lim _{n \rightarrow \infty}\left\|B^{*}\left(J_{E_{2}}\left(B x_{n}\right)-J_{E_{2}}\left(U\left(B x_{n}\right)\right)\right)\right\|=0 .
$$

In addition, combining (C2), (C3) and (25), we have

$$
\begin{aligned}
0 \leq a\left(1-t^{*}\right) \alpha(1-\eta)\left\|B x_{n}-U\left(B x_{n}\right)\right\|^{2} \leq & \alpha_{n} \phi\left(z, x_{n}\right)+\phi\left(z, x_{n}\right)-\phi\left(z, x_{n+1}\right) \\
& +\epsilon s^{2}\left\|B^{*}\left(J_{E_{2}}\left(B x_{n}\right)-J_{E_{2}}\left(U\left(B x_{n}\right)\right)\right)\right\|^{2} .
\end{aligned}
$$

It follows from (28) and (29) that

$$
\lim _{n \rightarrow \infty}|| J_{E_{2}}\left(B x_{n}\right)-J_{E_{2}}\left(U\left(B x_{n}\right)\right) \|=0
$$

as $n \rightarrow \infty$. Since $E_{2}$ is uniformly smooth, then, from (UM5) and (30), we obtain

$$
\lim _{n \rightarrow \infty}\left\|B\left(x_{n}\right)-U\left(B x_{n}\right)\right\|=\lim _{n \rightarrow \infty}\left\|J_{E_{2}}^{-1}\left(J_{E_{2}}\right)\left(B x_{n}\right)-J_{E_{2}}^{-1}\left(J_{E_{2}}\left(U\left(B x_{n}\right)\right)\right)\right\|=0 .
$$


Furthermore, using (10) and Lemma 4, we get

$$
\begin{aligned}
\phi\left(z, \bar{x}_{n+1}\right)= & \phi\left(z, J_{E_{1}}^{-1}\left(\beta_{n} J_{E_{1}} w_{n}+\left(1-\beta_{n}\right) J_{E_{1}} T_{\lambda} Q_{\mu_{n}} w_{n}\right)\right) \\
= & V\left(z, \beta_{n} J_{E_{1}} w_{n}+\left(1-\beta_{n}\right) J_{E_{1}} T_{\lambda} Q_{\mu_{n}} w_{n}\right) \\
= & \|z\|^{2}-2\left\langle z, \beta_{n} J_{E_{1}} w_{n}+\left(1-\beta_{n}\right) J_{E_{1}} T_{\lambda} Q_{\mu_{n}} w_{n}\right\rangle \\
& +\left\|\beta_{n} J_{E_{1}} w_{n}+\left(1-\beta_{n}\right) J_{E_{1}} T_{\lambda} Q_{\mu_{n}} w_{n}\right\|^{2} \\
= & \beta_{n}\left\|z_{n}\right\|^{2}+\left(1-\beta_{n}\right)\|z\|^{2}-2 \beta_{n}\left\langle z, J_{E_{1}} w_{n}\right\rangle-2\left(1-\beta_{n}\right)\left\langle z, J_{E_{1}} T_{\lambda} Q_{\mu_{n}} w_{n}\right\rangle \\
& +\beta_{n}\left\|J_{E_{1}} w_{n}\right\|^{2}+\left(1-\beta_{n}\right)\left\|J_{E_{1}} T_{\lambda} Q_{\mu_{n}} w_{n}\right\|^{2}-\beta_{n}\left(1-\beta_{n}\right) g\left(\left\|J_{E_{1}} w_{n}-J_{E_{1}} T_{\lambda} Q_{\mu_{n}} w_{n}\right\|\right) \\
\leq & \beta_{n} \phi\left(z, w_{n}\right)+\left(1-\beta_{n}\right) \phi\left(z, T_{\lambda} Q_{\mu_{n}} w_{n}\right) \\
& -\beta_{n}\left(1-\beta_{n}\right) g\left(\left\|J_{E_{1}} w_{n}-J_{E_{1}} T_{\lambda} Q_{\mu_{n}} w_{n}\right\|\right) \\
\leq & \phi\left(z, x_{n}\right)-\left(1-t_{n}\right) \beta_{n}\left(1-\beta_{n}\right) g\left(\left\|J_{E_{1}} w_{n}-J_{E_{1}} T_{\lambda} Q_{\mu_{n}} w_{n}\right\|\right) .
\end{aligned}
$$

In addition, with (20), (23) and (32), we get

$$
\begin{aligned}
\phi\left(z, x_{n+1}\right) \leq & \alpha_{n} \phi\left(z, u_{n}\right)+\left(1-\alpha_{n}\right)\left[t_{n} \phi\left(z, x_{n}\right)+\left(1-t_{n}\right) \phi\left(z, \bar{x}_{n+1}\right)\right] \\
\leq & \alpha_{n} \phi\left(z, u_{n}\right)+t_{n} \phi\left(z, x_{n}\right)+\left(1-t_{n}\right) \phi\left(z, \bar{x}_{n+1}\right) \\
\leq & \alpha_{n} \phi\left(z, u_{n}\right)+t_{n}\left(z, x_{n}\right) \\
& +\left(1-t_{n}\right)\left[\phi\left(z, x_{n}\right)-\beta_{n}\left(1-\beta_{n}\right) g\left(\left\|J_{E_{1}} w_{n}-J_{E_{1}} T_{\lambda} Q_{\mu_{n}} w_{n}\right\|\right)\right] \\
\leq & \alpha_{n} \phi\left(z, u_{n}\right)+\phi\left(z, x_{n}\right)-\beta_{n}\left(1-\beta_{n}\right) g\left(\left\|J_{E_{1}} w_{n}-J_{E_{1}} T_{\lambda} Q_{\mu_{n}} w_{n}\right\|\right) .
\end{aligned}
$$

Thus, from (C3) and (33), we obtain

$$
\begin{aligned}
0 & \left.\leq\left(1-t^{*}\right) \beta_{n}\left(1-\beta^{*}\right)\right) g\left(\left\|J_{E_{1}} w_{n}-J_{E_{1}} T_{\lambda} Q_{\mu_{n}} w_{n}\right\|\right) \\
& \left.\leq\left(1-t_{n}\right) \beta_{n}\left(1-\beta_{n}\right)\right) g\left(\left\|J_{E_{1}} w_{n}-J_{E_{1}} T_{\lambda} Q_{\mu_{n}} w_{n}\right\|\right) \\
& \leq \alpha_{n} \phi\left(z, u_{n}\right)+\phi\left(z, x_{n}\right)-\phi\left(z, x_{n+1}\right) .
\end{aligned}
$$

Then, using $(\mathrm{C} 1)$, we get

$$
\lim _{n \rightarrow \infty} g\left(\left\|J_{E_{1}} w_{n}-J_{E_{1}} T_{\lambda} Q_{\mu_{n}} w_{n}\right\|\right)=0
$$

Using property of $g$ in Lemma 4 , we obtain

$$
\lim _{n \rightarrow \infty}\left\|J_{E_{1}} w_{n}-J_{E_{1}} T_{\lambda} Q_{\mu_{n}} w_{n}\right\|=0
$$

Since $E_{1}^{*}$ is uniformly smooth, then, from (34), we get

$$
\lim _{n \rightarrow \infty}\left\|w_{n}-T_{\lambda} Q_{\mu_{n}} w_{n}\right\|=0
$$

In addition, by Lemma 9, (20) and (23), we get

$$
\begin{aligned}
\phi\left(z, x_{n+1}\right) \leq & \alpha_{n} \phi\left(z, u_{n}\right)+\left(1-\alpha_{n}\right)\left[t_{n} \phi\left(z, x_{n}\right)\right. \\
& \left.+\left(1-t_{n}\right)\left[\beta_{n} \phi\left(z, w_{n}\right)+\left(1-\beta_{n}\right)\left[\phi\left(z, w_{n}\right)-\phi\left(Q_{\mu_{n}} w_{n}, w_{n}\right)\right]\right]\right] \\
\leq & \alpha_{n} \phi\left(z, u_{n}\right)+\phi\left(z, x_{n}\right)-\left(1-\alpha_{n}\right)\left(1-t_{n}\right)\left(1-\beta_{n}\right) \phi\left(Q_{\mu_{n}} w_{n}, w_{n}\right) .
\end{aligned}
$$

Thus, using (C3), we have

$$
\begin{aligned}
0<\left(1-t^{*}\right)\left(1-\beta^{*}\right)\left(1-\alpha_{n}\right) \phi\left(Q_{\mu_{n}} w_{n}, w_{n}\right) & \leq\left(1-t_{n}\right)\left(1-\beta_{n}\right) \phi\left(Q_{\mu_{n}} w_{n}, w_{n}\right) \\
& \leq \alpha_{n} \phi\left(z, u_{n}\right)+\phi\left(z, x_{n}\right)-\phi\left(z, x_{n+1}\right)
\end{aligned}
$$

Then, applying (C1) and (28), we get

$$
\lim _{n \rightarrow \infty} \phi\left(Q_{\mu_{n}} w_{n}, w_{n}\right)=0
$$


From Lemma 5, we get

$$
\lim _{n \rightarrow \infty}\left\|Q_{\mu_{n}} w_{n}-w_{n}\right\|=0 .
$$

Since $E_{1}$ is uniformly smooth, then

$$
\lim _{n \rightarrow \infty}\left\|J_{E_{1}} Q_{\mu_{n}} w_{n}-J_{E_{1}} w_{n}\right\|=0 .
$$

It follows from (35) and (36) that

$$
\lim _{n \rightarrow \infty}\left\|T_{\lambda} Q_{\mu_{n}} w_{n}-Q_{\mu_{n}} w_{n}\right\|=0 .
$$

Since $E_{1}$ is uniformly smooth, then $J_{E_{1}}$ is uniformly norm-to-norm continuous on bounded subsets if $E_{1}$ and from (38), we obtain

$$
\lim _{n \rightarrow \infty}\left\|J_{E_{1}} T_{\lambda} Q_{\mu_{n}} w_{n}-J_{E_{1}} Q_{\mu_{n}} w_{n}\right\|=0
$$

As we know that $T_{\lambda}=J_{E_{1}}^{-1}\left((1-\lambda) J_{E_{1}}+\lambda J_{E_{1}} T\right)$, thus

$$
\left\|J_{E_{1}} T_{\lambda} Q_{\mu_{n}} w_{n}-J_{E_{1}} Q_{\mu_{n}} w_{n}\right\|=\lambda\left\|J_{E_{1}} T Q_{\mu_{n}} w_{n}-J_{E_{1}} Q_{\mu_{n}} w_{n}\right\|
$$

Since $\lambda>0$, it follows from (39) that

$$
\lim _{n \rightarrow \infty}\left\|J_{E_{1}} T Q_{\mu_{n}} w_{n}-J_{E_{1}} Q_{\mu_{n}} w_{n}\right\|=0
$$

Thus, we have

$$
\lim _{n \rightarrow \infty}\left\|T Q_{\mu_{n}} w_{n}-Q_{\mu_{n}} w_{n}\right\|=0
$$

In addition, since $\left\{\alpha_{n}\right\} \subset(0,1)$, then

$$
\begin{aligned}
\phi\left(z, x_{n+1}\right) \leq & \alpha_{n} \phi\left(z, u_{n}\right)+\left(1-\alpha_{n}\right) \phi\left(z, Q_{\mu_{n}} y_{n}\right) \\
\leq & \alpha_{n} \phi\left(z, u_{n}\right)+\left(1-\alpha_{n}\right) \phi\left(z, y_{n}\right) \\
\leq & \alpha_{n} \phi\left(z, u_{n}\right)+\phi\left(z, J_{E_{1}}^{-1}\left(t_{n} J_{E_{1}} x_{n}+\left(1-t_{n}\right) J_{E_{1}} \bar{x}_{n+1}\right)\right) \\
= & \alpha_{n} \phi\left(z, u_{n}\right)+V\left(z, t_{n} J_{E_{1}} x_{n}+\left(1-t_{n}\right) J_{E_{1}} \bar{x}_{n+1}\right) \\
= & \alpha_{n} \phi\left(z, u_{n}\right)+\|z\|^{2}-2\left\langle z, t_{n} J_{E_{1}} x_{n}+\left(1-t_{n}\right) J_{E_{1}} \bar{x}_{n+1}\right\rangle \\
& +\left\|t_{n} J_{E_{1}} x_{n}+\left(1-t_{n}\right) J_{E_{1}} \bar{x}_{n+1}\right\|^{2} \\
\leq & \alpha_{n} \phi\left(z, u_{n}\right)+t_{n} \phi\left(z, x_{n}\right)+\left(1-t_{n}\right) \phi\left(z, \bar{x}_{n+1}\right) \\
& -t_{n}\left(1-t_{n}\right)\left\|J_{E_{1}} x_{n}-J_{E_{1}} \bar{x}_{n+1}\right\|^{2} \\
= & \alpha_{n} \phi\left(z, u_{n}\right)+\phi\left(z, x_{n}\right)-t_{n}\left(1-t_{n}\right)\left\|J_{E_{1}} x_{n}-J_{E_{1}} \bar{x}_{n+1}\right\|^{2} .
\end{aligned}
$$

It follows from (C1), (C3) and (28) that

$$
\begin{aligned}
0 & \leq t\left(1-t^{*}\right)\left\|J_{E_{1}} x_{n}-J_{E_{1}} \bar{x}_{n+1}\right\|^{2} \leq t_{n}\left(1-t_{n}\right)\left\|J_{E_{1}} x_{n}-J_{E_{1}} \bar{x}_{n+1}\right\|^{2} \\
& \leq \alpha_{n} \phi\left(z, u_{n}\right)+\phi\left(z, x_{n}\right)-\phi\left(z, x_{n+1}\right) \rightarrow 0 \text { as } n \rightarrow \infty
\end{aligned}
$$

Hence,

$$
\lim _{n \rightarrow \infty}\left\|J_{E_{1}} x_{n}-J_{E_{1}} \bar{x}_{n+1}\right\|=0 .
$$

This implies that

$$
\lim _{n \rightarrow \infty}|| x_{n}-\bar{x}_{n+1} \|=0 .
$$


In addition, from (A3) and (17), we get

$$
\begin{aligned}
\left.\phi\left(y_{n}, \bar{x}_{n+1}\right)\right] & \leq t_{n} \phi\left(x_{n}, \bar{x}_{n+1}\right)+\left(1-t_{n}\right) \phi\left(\bar{x}_{n+1}, \bar{x}_{n+1}\right) \\
& \leq t_{n}\left[\left\|x_{n}|||| J_{E_{1}} x_{n}-J_{E_{1}} \bar{x}_{n+1}\right\|+|| \bar{x}_{n+1}|||| x_{n}-\bar{x}_{n+1}||\right] .
\end{aligned}
$$

It follows from (42) and (43) that

$$
\lim _{n \rightarrow \infty} \phi\left(y_{n}, \bar{x}_{n+1}\right)=0
$$

Thus, from Lemma 5, we get

$$
\lim _{n \rightarrow \infty}\left\|y_{n}-\bar{x}_{n+1}\right\|=0 .
$$

Using Lemma 9, $\left(x_{n+1}\right)$ in (17) and by (22), we have

$$
\begin{aligned}
\phi\left(Q_{\mu_{n}} y_{n}, y_{n}\right) \leq & \phi\left(z, y_{n}\right)-\phi\left(z, Q_{\mu_{n}} y_{n}\right) \\
= & \phi\left(z, y_{n}\right)-\phi\left(z, x_{n+1}\right)+\phi\left(z, x_{n+1}\right)-\phi\left(z, Q_{\mu_{n}} y_{n}\right) \\
\leq & \phi\left(z, x_{n}\right)-\phi\left(z, x_{n+1}\right)+\alpha_{n} \phi\left(z, u_{n}\right) \\
& +\left(1-\alpha_{n}\right) \phi\left(z, Q_{\mu} y_{n}\right)-\phi\left(z, Q_{\mu} y_{n}\right) \\
\leq & \phi\left(z, x_{n}\right)-\phi\left(z, x_{n+1}\right)+\alpha_{n}\left[\phi\left(z, u_{n}\right)-\phi\left(z, Q_{\mu} y_{n}\right)\right] .
\end{aligned}
$$

It follows from (C1) and (28) that

$$
\lim _{n \rightarrow \infty} \phi\left(Q_{\mu_{n}} y_{n}, y_{n}\right)=0,
$$

and, by Lemma 5, we have

$$
\lim _{n \rightarrow \infty}\left\|Q_{\mu_{n}} y_{n}-y_{n}\right\|=0 .
$$

Combining (17) and (C1), we have

$$
\phi\left(Q_{\mu_{n}} y_{n}, x_{n+1}\right) \leq \alpha_{n} \phi\left(Q_{\mu_{n}} y_{n}, u_{n}\right)+\left(1-\alpha_{n}\right) \phi\left(Q_{\mu_{n}} y_{n}, Q_{\mu_{n}} y_{n}\right), \rightarrow 0
$$

as $n \rightarrow \infty$; thus, with Lemma 5 , we obtain

$$
\lim _{n \rightarrow \infty}\left\|Q_{\mu_{n}} y_{n}-x_{n+1}\right\|=0 .
$$

Since

$$
\begin{aligned}
\left\|x_{n}-x_{n+1}\right\| \leq & \left\|x_{n}-\bar{x}_{n+1}\right\|+\left\|\bar{x}_{n+1}-y_{n}\right\|+\left\|y_{n}-Q_{\mu_{n}} y_{n}\right\| \\
& +\left\|Q_{\mu_{n}} y_{n}-x_{n+1}\right\|,
\end{aligned}
$$

then it follows from (43), (45), (47) and (49) that

$$
\lim _{n \rightarrow \infty}|| x_{n}-x_{n+1} \|=0 .
$$

Furthermore, since $E_{1}$ is reflexive and $\left\{x_{n}\right\}_{n=1}^{\infty}$ is bounded, then there exists a subsequence $\left\{x_{n_{j}}\right\}$ of $\left\{x_{n}\right\}$ such that $\left\{x_{n_{j}}\right\}$ converges weakly to $x^{*}$ in $E_{1}$. In addition, we know that $B$ is linear and bounded, then it is continuous, so $x_{n_{j}} \rightarrow x^{*}$ implies that $B x_{n_{j}} \rightarrow B x^{*}$. Thus, by (31), we have $\lim _{n \rightarrow \infty}\left\|B x_{n}-U\left(B x_{n}\right)\right\|=0$ and, since $U$ is demiclosed at zero, then, $B x^{*}=U\left(B x^{*}\right)$, that is, $x^{*} \in B^{-1}(F(U))$. From (30), we get $\lim _{n \rightarrow \infty}\left\|x_{n}-w_{n}\right\|=0$, thus $w_{n_{j}} \rightarrow x^{*}$, so, using (36) it implies that $\left\{Q_{\mu_{j}} w_{n_{j}}\right\}$ converges weakly to $x^{*}$. Since $Q_{\mu_{n}}$ is generalized resolvent of $A$ in $E_{1}$, then 


$$
\frac{J_{E_{1}} w_{n}-J_{E_{1}} Q_{\mu_{n}} w_{n}}{\mu_{n}} \in A Q_{\mu_{n}} w_{n}, \forall n \geq 1 .
$$

Since $A$ is monotone, we have

$$
0 \leq\left\langle c-Q_{\mu_{n_{j}}} w_{n_{j}}, d-\frac{J_{E_{1}} w_{n_{j}}-J_{E_{1}} Q_{\mu_{n_{j}}} w_{n_{j}}}{\mu_{n_{j}}}\right\rangle,
$$

for all $(c, d) \in A$ and we know from (37) that $\lim _{j=\infty}|| J_{E_{1}} w_{n_{j}}-J_{E_{1}} Q_{\mu_{n_{j}}} w_{n_{j}}||=0$, then, since $\mu_{n_{j}}>0$ for all $j \geq 1$, we have that $\left\langle c-x^{*}, d-0\right\rangle \geq 0$ for all $(c, d) \in A$ and with the fact that $A$ is maximal monotone, we obtain $x^{*} \in A^{-1}(0)$. In addition, since $Q_{\mu_{n_{j}}} w_{n_{j}} \rightarrow x^{*}$, we know from (41) that $\lim _{n \rightarrow \infty}\left\|Q_{\mu_{n}} w_{n}-T\left(Q_{\mu_{n}} w_{n}\right)\right\|=0$; then, using the fact that $T$ is demiclosed at zero, we obtain $x^{*} \in F(T)$. Therefore, $x^{*} \in \Gamma:=F(T) \cap A^{-1}(0) \cap B^{-1}(F(U))$.

Next, we show that $\left\{x_{n}\right\}$ converges strongly to $\Pi_{\Gamma} u$. Letting $z^{*}=\Pi_{\Gamma} u$, since $x_{n_{j}}$ converges weakly to $x^{*}$, then, using Lemma 2 , we get

$$
\begin{aligned}
\limsup _{n \rightarrow \infty}\left\langle x_{n}-z^{*}, J_{E_{1}}\left(u_{n}\right)-J_{E_{1}} z^{*}\right\rangle & =\lim _{j \rightarrow \infty}\left\langle x_{n_{j}}-z^{*}, J_{E_{1}}\left(u_{n_{j}}\right)-J_{E_{1}} z^{*}\right\rangle \\
& =\left\langle x^{*}-z^{*}, J_{E_{1}}(u)-J_{E_{1}} z^{*}\right\rangle \leq 0 .
\end{aligned}
$$

Observe that

$$
\left\langle x_{n+1}-z^{*}, J_{E_{1}}\left(u_{n}\right)-J_{E_{1}} z^{*}\right\rangle=\left\langle x_{n+1}-x_{n}, J_{E_{1}}\left(u_{n}\right)-J_{E_{1}} z^{*}\right\rangle+\left\langle x_{n}-z^{*}, J_{E_{1}}\left(u_{n}\right)-J_{E_{1}} z^{*}\right\rangle .
$$

It follows from (50) and (51) that

$$
\limsup _{n \rightarrow \infty}\left\langle x_{n+1}-z^{*}, J_{E_{1}}\left(u_{n}\right)-J_{E_{1}}\left(z^{*}\right)\right\rangle \leq 0 .
$$

Finally, using (11), Lemma 1, and (22), we obtain

$$
\begin{aligned}
\phi\left(z^{*}, x_{n+1}\right)= & \phi\left(z^{*}, J_{E_{1}}^{-1}\left(\alpha_{n}\right) J_{E_{1}} u_{n}+\left(1-\alpha_{n}\right) J_{E_{1}} Q_{\mu_{n}} y_{n}\right) \\
= & \left.V\left(z^{*}, \alpha_{n}\right) J_{E_{1}} u_{n}+\left(1-\alpha_{n}\right) J_{E_{1}} Q_{\mu_{n}} y_{n}\right) \\
\leq & V\left(z^{*}, \alpha_{n} J_{E_{1}} u_{n}+\left(1-\alpha_{n}\right) J_{E_{1}} Q_{\mu_{n}} y_{n}-\alpha_{n}\left(J_{E_{1}} u_{n}-J_{E_{1}} z^{*}\right)\right) \\
& -2\left\langle x_{n+1}-z^{*},-\alpha_{n}\left(J_{E_{1}} u_{n}-J_{E_{1}} z^{*}\right)\right\rangle \\
\leq & \left(1-\alpha_{n}\right) \phi\left(z^{*}, x_{n}\right)+2 \alpha_{n}\left\langle x_{n+1}-z^{*}, J_{E_{1}} u_{n}-J_{E_{1}} z^{*}\right\rangle .
\end{aligned}
$$

Thus, with the help of (C1), (52) and applying Lemma 12, we get $\phi\left(z^{*}, x_{n}\right) \rightarrow 0$ as $n \rightarrow \infty$; then, by Lemma 6, we obtain $\left\|x_{n}-z^{*}\right\| \rightarrow 0$ as $n \rightarrow \infty$. Hence, $x_{n} \rightarrow z^{*}:=\Pi_{\Gamma} u$, where $\Gamma:=F(T) \cap A^{-1}(0) \cap B^{-1}(F(U))$.

Case II: Suppose that $\left\{\phi\left(z, x_{n}\right)\right\}_{n=1}^{\infty}$ is not a non-increasing sequence. Then, let $\left\{x_{n_{i}}\right\}$ be a subsequence of $\left\{x_{n}\right\}$ such that $\phi\left(z, x_{n_{i}}\right)<\phi\left(z, x_{n_{i}+1}\right)$ for all $i \in \mathbb{N}$. Then, by Lemma 13, there exists a nondecreasing sequence $\left\{m_{s}\right\} \subseteq \mathbb{N}$ such that $m_{s} \rightarrow \infty$ as $s \rightarrow \infty$,

$$
\phi\left(z, x_{m_{s}}\right) \leq \phi\left(z, x_{m_{s}+1}\right) \quad \text { and } \phi\left(z, x_{s}\right) \leq \phi\left(z, x_{m_{s}+1}\right) .
$$

Since $\left\{\phi\left(z, x_{m_{s}}\right)\right\}$ is bounded, then $\lim _{s \rightarrow \infty} \phi\left(z, x_{m_{s}}\right)$ exists. Therefore, using the same method of arguments as in Case I (from (30)-(50)), we get

$$
\lim _{s \rightarrow \infty}|| x_{m_{s}+1}-x_{m_{s}}||=0 .
$$

Similarly as in the proof of Case 1, we obtain

$$
\limsup _{m \rightarrow \infty}\left\langle x_{m_{s}+1}-z^{*}, J_{E_{1}}\left(u_{m_{s}}\right)-J_{E_{1}} z^{*}\right\rangle \leq 0 .
$$


In addition, from (53), we have

$$
\phi\left(z^{*}, x_{m_{s}+1}\right) \leq\left(1-\alpha_{m_{s}}\right) \phi\left(z^{*}, x_{m_{s}}\right)+2 \alpha_{m_{s}}\left\langle x_{m_{s}+1}-z^{*}, J_{E_{1}} u_{m_{s}}-J_{E_{1}} z^{*}\right\rangle
$$

which implies

$$
\alpha_{m_{s}} \phi\left(z^{*}, x_{m_{s}}\right) \leq \phi\left(z^{*}, x_{m_{s}}\right)-\phi\left(z^{*}, x_{m_{s}+1}\right)+2 \alpha_{m_{s}}\left\langle x_{m_{s}+1}-z^{*}, J_{E_{1}} u_{m_{s}}-J_{E_{1}} z^{*}\right\rangle
$$

and, since $\alpha_{m_{s}}>0$ for all $s \in \mathbb{N}$ and $\phi\left(z^{*}, x_{m_{s}}\right) \leq \phi\left(z^{*}, x_{m_{s}+1}\right)$, then

$$
\phi\left(z^{*}, x_{m_{s}}\right) \leq 2\left\langle x_{m_{s}+1}-z^{*}, J_{E_{1}} u_{m_{s}}-J_{E_{1}} z^{*}\right\rangle .
$$

Hence, from (54), we obtain $\lim _{s \rightarrow \infty} \phi\left(z^{*}, x_{m_{s}}\right)=0$, then, with (55), we have $\lim _{s \rightarrow \infty} \phi\left(z^{*}\right.$, $\left.x_{m_{s}+1}\right)=0$. However, we know that $\phi\left(z^{*}, x_{s}\right) \leq \phi\left(z^{*}, x_{m_{s}+1}\right)$ for all $s \in \mathbb{N}$, thus $\lim _{s \rightarrow \infty} \phi\left(z^{*}\right.$, $\left.x_{s}\right)=0$. Therefore, using Lemma 6 , we obtain $\left\|x_{s}-z^{*}\right\| \rightarrow 0$ as $s \rightarrow \infty$. Hence, $x_{s} \rightarrow z^{*}:=$ $\Pi_{\Gamma} u$, where $\Gamma:=F(T) \cap A^{-1}(0) \cap B^{-1}(F(U))$. This completes the proof.

We obtained the following results as the consequences of our main result.

(i) Let $C$ and $Q$ be nonempty, closed, and a convex subset of $E_{1}$ and $E_{2}$, respectively. Taking $A=\partial_{N_{C}}$, the normal cone operator at $C$ which is maximally monotone (see [32]) and defined by

$$
N_{C}(x)= \begin{cases}\varnothing, & \text { if } \quad x \notin C, \\ \{w:\langle w, z-x\rangle \leq 0, \quad \forall z \in C\} & \text { if } \quad x \in C,\end{cases}
$$

then the resolvent operator with respect to $A$ is the projection operator $\Pi_{C}$. In addition, taking $U=P_{Q}$, the metric projection from $E_{2}$ onto $Q$, then the GSFP reduces to the SFP. Note that the class of $(0,0)$-demigeneralized mapping is nonexpansive. Hence, from Theorem 1 , we obtained the following result for solving SFP in real Banach spaces.

Corollary 1. Let $C$ and $Q$ be nonempty, closed and convex subsets of two uniformly smooth and 2-uniformly convex real Banach spaces $E_{1}$ and $E_{2}$, respectively. Let $J_{E_{1}}$ and $J_{E_{2}}$ be normalized duality mappings on $E_{1}$ and $E_{2}$, respectively. Let $T: E_{1} \rightarrow E_{1}$ be a $(\eta, 0)$-demigeneralized mapping and demiclosed at zero with $\eta \in(-\infty, \lambda]$ and $\lambda \in[0,1)$ such that $F(T) \neq \varnothing$. Let $B: E_{1} \rightarrow E_{2}$ be a bijective bounded linear operator with its adjoint $B^{*}: E_{2}^{*} \rightarrow E_{1}^{*}$. Suppose that $\Gamma=F(T) \cap \operatorname{SFP}(C, Q, B) \neq \varnothing$. Let $\left\{u_{n}\right\}$ be a sequence in $E_{1}$ such that $u_{n} \rightarrow u \in E_{1}$ and for any arbitrary sequence $\left\{x_{n}\right\}_{n=1}^{\infty}$ in $E_{1}$ generated by $x_{1} \in E_{1}$ and

$$
\left\{\begin{array}{l}
w_{n}=J_{E_{1}}^{-1}\left(J_{E_{1}} x_{n}-\gamma_{n} B^{*}\left(J_{E_{2}}\left(B x_{n}\right)-J_{E_{2}} P_{Q}\left(B x_{n}\right)\right)\right) \\
\bar{x}_{n+1}=J_{E_{1}}^{-1}\left(\beta_{n} J_{E_{1}}\left(w_{n}\right)+\left(1-\beta_{n}\right) J_{E_{1}} T_{\lambda} \Pi_{C}\left(w_{n}\right)\right) \\
x_{n+1}=J_{E_{1}}^{-1}\left[\alpha_{n} J_{E_{1}}\left(u_{n}\right)+\left(1-\alpha_{n}\right) J_{E_{1}} \Pi_{C} J^{-1}\left(\left(t_{n} J_{E_{1}}\left(x_{n}\right)+\left(1-t_{n}\right) J_{E_{1}} \bar{x}_{n+1}\right)\right)\right], n \geq 1
\end{array}\right.
$$

where $T_{\lambda}=J_{E_{1}}^{-1}\left((1-\lambda) J_{E_{1}}+\lambda J_{E_{1}} T\right),\left\{\alpha_{n}\right\},\left\{\beta_{n}\right\}$, and $\left\{t_{n}\right\}$ are sequences in $(0,1)$ and $\mu_{n} \subset(0, \infty)$. Suppose that the following conditions are satisfied:

(C1) $\lim _{n \rightarrow \infty} \alpha_{n}=0$ and $\sum_{n=1}^{\infty} \alpha_{n}=\infty$;

(C2) for any $\alpha>0$ as in Lemma 6 and any fixed value $a>0$, the stepsize $\gamma_{n}$ is chosen as follows

$$
0<a \leq \gamma_{n} \leq \frac{\alpha(1-\theta)\left\|B x_{n}-P_{Q} B x_{n}\right\|^{2}}{\left\|B^{*}\left(J_{E_{2}}\left(B x_{n}\right)-J_{E_{2}}\left(P_{Q} B x_{n}\right)\right)\right\|^{2}}-a,
$$

if $B x_{n} \neq P_{Q} B x_{n}$; otherwise, $\gamma_{n}=\gamma(\gamma \geq 0)$.

(C3) $0<t \leq t_{n} \leq t^{*}<1$ and $0<\beta \leq \beta_{n} \leq \beta^{*}<1$, where $\left[t, t^{*}\right] \subset(0,1),\left[\beta, \beta^{*}\right] \subset(0,1)$.

Then, $\left\{x_{n}\right\}_{n=1}^{\infty}$ converges strongly to $z^{*} \in \Gamma$, where $z^{*}=\Pi_{\Gamma} u$. 
(ii) When $E_{1}=H_{1}$ and $E_{2}=H_{2}$, where $H_{1}$ and $H_{2}$ are real Hilbert spaces, we obtained the following generalized explicit algorithm for solving the GSFP in real Hilbert spaces.

Corollary 2. Let $H_{1}$ and $H_{2}$ be real Hilbert spaces. Let $T: H_{1} \rightarrow H_{1}$ be a $(\eta, 0)$-demigeneralized mapping and demiclosed at zero with $\eta \in(-\infty, \lambda]$ and $\lambda \in[0,1)$ such that $F(T) \neq \varnothing$. Let $U: \mathrm{H}_{2} \rightarrow \mathrm{H}_{2}$ be a $(\theta, 0)$-demigeneralized mapping and demiclosed at zero with $\theta \in(-\infty, 0]$ such that $F(U) \neq \varnothing$. Let $A$ be a maximal monotone operator of $H$ into $2^{H}$ such that $A^{-1} \neq \varnothing$ and $J_{\mu}^{A}$ are the resolvent operator of $A$ for $\mu>0$. Let $T: C \rightarrow H$ be a $(k, 0)$-demigeneralized mapping and demiclosed at zero with $k \in(-\infty, 0]$. Let $B: H_{1} \rightarrow H_{2}$ be a bijective bounded linear operator with its adjoint $H^{*}: H_{2}^{*} \rightarrow H_{1}^{*}$. Suppose that $\Gamma=F(T) \cap A^{-1}(0) \cap B^{-1} F(U) \neq \varnothing$. Let $\left\{u_{n}\right\}$ be a sequence in $H_{1}$ such that $u_{n} \rightarrow u \in E_{1}$ and for any arbitrary sequence $\left\{x_{n}\right\}_{n=1}^{\infty}$ in $H_{1}$ generated by $x_{1} \in H_{1}$ and

$$
\left\{\begin{array}{l}
w_{n}=x_{n}-\gamma_{n} B^{*}\left(B x_{n}\right)-U\left(B x_{n}\right) \\
\bar{x}_{n+1}=\beta_{n} w_{n}+\left(1-\beta_{n}\right) T_{\lambda} J_{\mu_{n}}^{B} w_{n} \\
x_{n+1}=\alpha_{n} u_{n}+\left(1-\alpha_{n}\right) J_{\mu_{n}}^{B}\left(t_{n} x_{n}+\left(1-t_{n}\right) \bar{x}_{n+1}\right), \quad n \geq 1
\end{array}\right.
$$

where $T_{\lambda}=(1-\lambda)+\lambda T,\left\{\alpha_{n}\right\},\left\{\beta_{n}\right\}$ and $\left\{t_{n}\right\}$ are sequences in $(0,1)$ and $\mu_{n} \subset(0, \infty)$. Suppose the following conditions are satisfied:

(C1) $\lim _{n \rightarrow \infty} \alpha_{n}=0$ and $\sum_{n=1}^{\infty} \alpha_{n}=\infty$;

(C2) for any $\alpha>0$ as in Lemma 6 and any fixed value $a>0$, the stepsize $\gamma_{n}$ is chosen as follows

$$
0<a \leq \gamma_{n} \leq \frac{\alpha(1-\theta)\left\|B x_{n}-U B x_{n}\right\|^{2}}{\left\|B^{*}\left(B x_{n}-U B x_{n}\right)\right\|^{2}}-a,
$$

if $B x_{n} \neq U B x_{n} ;$ otherwise $\gamma_{n}=\gamma(\gamma \geq 0)$.

(C3) $0<t \leq t_{n} \leq t^{*}<1$ and $0<\beta \leq \beta_{n} \leq \beta^{*}<1$, where $\left[t, t^{*}\right] \subset(0,1),\left[\beta, \beta^{*}\right] \subset(0,1)$.

Then, $\left\{x_{n}\right\}_{n=1}^{\infty}$ converges strongly to $z^{*} \in \Gamma$, where $z^{*}=P_{\Gamma} u$ and $P_{\Gamma}$ is the metric projection onto $\Gamma$.

\section{Numerical Examples}

In this section, we present some numerical examples to illustrate the efficiency and performance of the proposed algorithm. We compare the performance of our iteration (17) with (4)-(6). The numerical computations are carried out using MATLAB 2019b on a PC with specification Intel(R)core i7-600, CPU 2.48 GHz, RAM 8.0 GB.

Example 1. Let $E_{1}=E_{2}=\ell_{2}(\mathbb{R})$, where $\ell_{2}(\mathbb{R})=\left\{u=\left(u_{1}, u_{2}, \ldots, u_{k}, \ldots\right), u_{k} \in \mathbb{R}\right.$ : $\left.\sum_{k=1}^{\infty}\left|u_{k}\right|^{2}<\infty\right\},\|u\|_{\ell_{2}}=\left(\sum_{k=1}^{\infty}\left|u_{k}\right|^{2}\right)^{\frac{1}{2}}$ for all $u \in E_{1}$. Let $A: \ell_{2} \rightarrow \ell_{2}$ and $B: \ell_{2} \rightarrow \ell_{2}$ be two mappings defined by

$$
A u=2 u+(1,1,0,0, \ldots) \text { and } B u=3 u,
$$

where $u=\left(u_{1}, u_{2}, \ldots, u_{k}, \ldots\right) \in \ell_{2}$. We see that $A$ is maximal monotone and $B$ is a bounded linear operator. In addition, we define the mappings $T: \ell_{2} \rightarrow \ell_{2}$ and $U: \ell_{2} \rightarrow \ell_{2}$ by $\mathrm{Tu}=$ $\left(\frac{-3 u_{1}}{2}, \frac{-3 u_{2}}{2}, \ldots, \frac{-3 u_{k}}{2}, \ldots\right)$ and $U v=\left(\frac{v_{1}}{2}, \frac{v_{2}}{2}, \ldots, \frac{v_{k}}{2}, \ldots\right)$ for $u=\left(u_{1}, u_{2}, \ldots, u_{k}, \ldots\right) \in \ell_{2}$ and $v=\left(v_{1}, v_{2}, \ldots, v_{k}, \ldots\right) \in \ell_{2}$. Then, $T$ and $U$ are $\left(\frac{1}{5}, 0\right)$ and $(0,0)$-demigeneralized mappings, respectively, and demiclosed at zero. We choose $\alpha_{n}=\frac{1}{n+1}, t_{n}=\frac{2 n}{5 n+1}, \beta_{n}=\frac{1}{3}-\frac{1}{3(n+1)}$, $\alpha=0.2, \lambda=0.025$. Thus, our iterative scheme (17) becomes:

$$
\left\{\begin{array}{l}
w_{n}=J_{E_{1}}^{-1}\left(J_{E_{1}}\left(x_{n}\right)-\gamma_{n} B^{*}\left(J_{E_{2}}\left(B x_{n}\right)-J_{E_{2}}\left(U B x_{n}\right)\right)\right), \\
\bar{x}_{n+1}=J_{E_{1}}^{-1}\left(\frac{n}{3(n+1)} J_{E_{1}}\left(w_{n}\right)+\frac{2 n+3}{3(n+1)} J_{E_{1}} T_{\lambda} Q_{\mu_{n}}\left(w_{n}\right)\right), \\
x_{n+1}=J_{E_{1}}^{-1}\left(\frac{1}{n+1} J_{E_{1}}\left(u_{n}\right)+\frac{n}{n+1} J_{E_{1}} Q_{\mu_{n}} J^{-1}\left(\left(\frac{2 n}{5 n+1} J_{E_{1}}\left(x_{n}\right)+\frac{3 n+1}{5 n+1} J_{E_{1}}\left(x_{n+1}\right)\right)\right)\right),
\end{array}\right.
$$


where $T_{\lambda} x=J_{E_{1}}^{-1}\left(0.975 J_{E_{1}}(x)+0.025 J_{E_{1}}+E_{1}(T x)\right)$. Since $E_{1}=E_{2}=\ell_{2}(\mathbb{R})$, the duality mappings $J_{E_{i}}(i=1,2)$ and $J_{E_{1}}^{-1}$ reduce to the identity mappings on $\ell_{2}$. We compare the performance of (58) with the iterative scheme (6) of [9], (5) of [8] and (4) of [7]. For iteration (6), $U$ is defined as above, which is 0-quasi-strict pseudocontractive mapping and $F(U) \neq \varnothing$. In addition, we take $\alpha_{n}=\frac{1}{n+1}$ and $\gamma=\frac{1}{2\|B\|^{2}}$. For iteration (5), we consider the case for which $i=1$, and we take $\alpha_{n}=\frac{1}{n+1}, \beta_{n}=\frac{2 n}{3 n+3}, \gamma_{n}=1-\alpha_{n}-\beta_{n} . \delta_{n}=\frac{1}{\|A\|^{2}}$, while, for iteration (4), we choose $\beta_{n}=\frac{2 n}{5 n+1}$. We study the convergence of the algorithms using $D_{n}=\left\|x_{n+1}-x_{n}\right\|<10^{-6}$ as a stopping criterion. We test the algorithms using the following initial values:

Case I: $x_{0}=\left(\frac{1}{2}, \frac{1}{4}, \frac{1}{8}, \ldots\right)$,

Case II: $x_{0}=(5,5,5, \ldots)$;

Case III: $x_{0}=(-3,9,-27, \ldots)$;

Case IV: $x_{0}=(2,2,0,0, \ldots)$.

The computational results are shown in Table 1 and Figure 1.
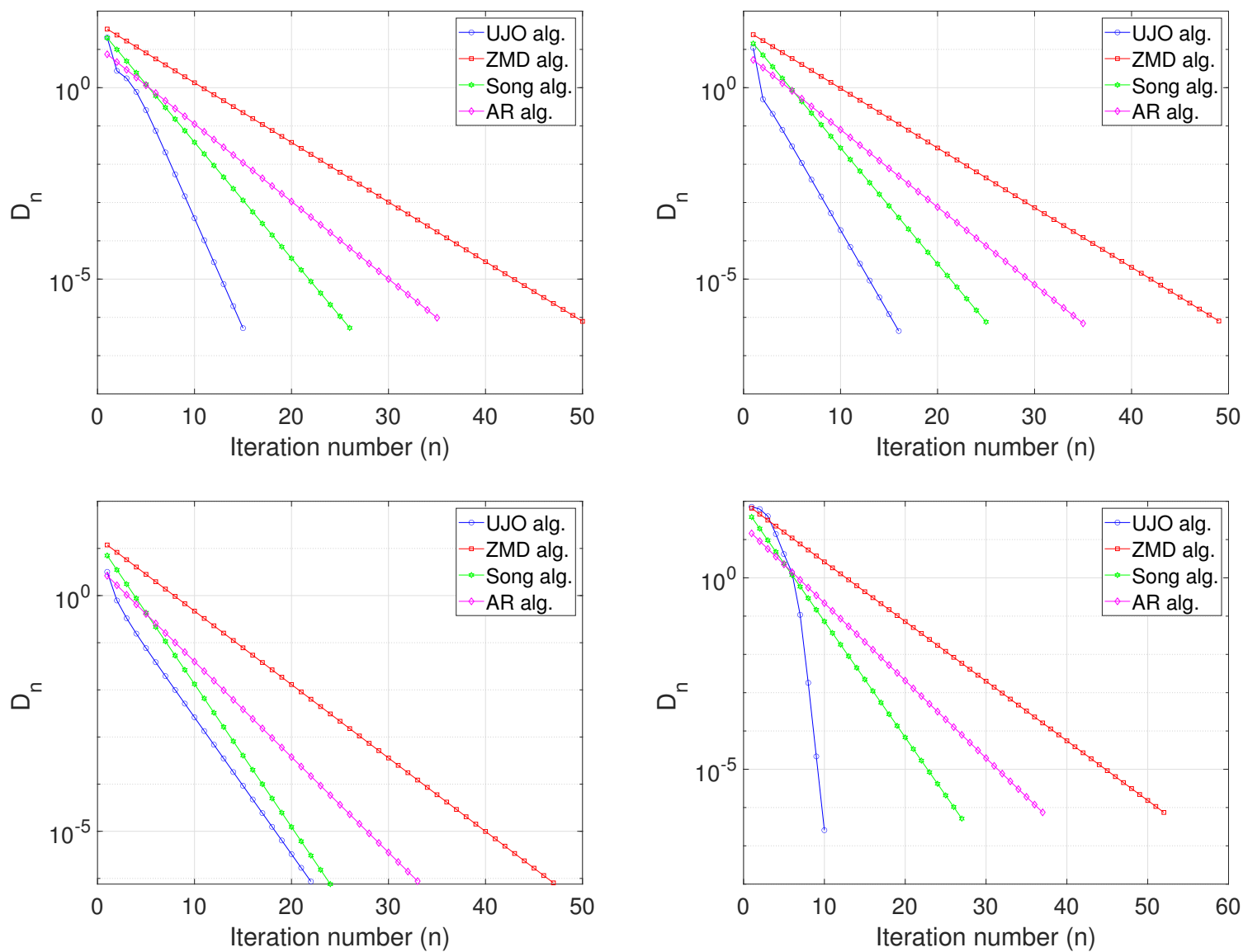

Figure 1. Example 1, Top Left: Case I; Top Right: Case II; Bottom Left: Case III; Bottom Right: Case IV.

Example 2. Next, we present an example in real Banach spaces. Let $E_{1}=E_{2}=L_{p}([0,2 \pi])$ (for $p \in(0,2])$ with norm $\|x\|_{L_{p}}=\left(\int_{0}^{2 \pi}|x(t)|^{p} d t\right)^{\frac{1}{p}}$ and inner product $\langle x, y\rangle=\int_{0}^{2 \pi} x(t) y(t) d t$ for all $x, y \in L_{p}([0,2 \pi])$. Let $C=\left\{x \in L_{p}([0,2 \pi]):\left\langle 3 t^{2}, x\right\rangle \leq 1\right\}$. The duality mapping is defined by (see [33])

$$
J_{E}(x)(t)=|x(t)|^{p-1} \operatorname{sgn}(x(t)) .
$$

Define the operator $A \equiv \partial i_{C}$; then, $A$ is maximal monotone and the resolvent $Q_{\mu}$ is the projection operator onto $C$ which is given by 


$$
\Pi_{C}(x)(t)= \begin{cases}x(t)-\frac{\left\langle 3 t^{2}, x\right\rangle}{\left\|3 t^{2}\right\|^{2}} 3 t^{2} & \text { if }\left\langle 3 t^{2}, x\right\rangle>1 \\ x(t) & \text { if }\left\langle 3 t^{2}, x\right\rangle \leq 1\end{cases}
$$

Furthermore, let $Q=\left\{y \in L_{p}([0,2 \pi]):\left\langle\frac{t}{3}, y\right\rangle=0\right\}$. Then, projection onto $Q$ is given by

$$
\Pi_{Q}(y)(t)= \begin{cases}y(t)-\frac{\left\langle\frac{t}{3}, y\right\rangle}{\left\|^{\frac{t}{3}}\right\|^{2}} \frac{t}{3} & \text { if }\left\langle\frac{t}{3}, y\right\rangle \neq 0, \\ y(t) & \text { if }\left\langle\frac{t}{3}, y\right\rangle=0 .\end{cases}
$$

We set $T=\Pi_{C}$ and $U=\Pi_{Q}$; then, $T$ and $U$ are $(0,0)$-demigeneralized mappings. In addition, let $B: L_{p}([0,2 \pi]) \rightarrow L_{p}([0,2 \pi])$ be defined by $B x(t)=\frac{x(t)}{2}$ for all $x \in L_{p}([0,2 \pi])$. In particular, we take $p=\frac{3}{2}$ so that $E$ is not a real Hilbert space. We choose the following parameters and compare our method with the methods of Zi et al. [9] (Algorithm 1.6): For Algorithm 17, we take $\alpha_{n}=\frac{1}{100(n+1)}, \beta_{n}=\frac{30 n}{50 n+1}, t_{n}=\frac{3}{5}, \lambda=0.03, \alpha=0.1$ and, for Algorithm 1.6, we take $\alpha_{n}=\frac{1}{100(n+1)}, \gamma=\frac{1}{100}$. We test the algorithms for the following initial values:

Case I: $x_{0}=\frac{\exp (3 t)}{30}$;

Case II: $x_{0}=2 t \cos \left(5 t^{2}\right)$;

Case III: $x_{0}=t^{3}-27$

Case IV: $x_{0}=3 t \exp (7 t)$.

Using $\left\|x_{n+1}-x_{n}\right\|_{L_{p}}<10^{-4}$, we plot the graphs of error $\left(\left\|x_{n+1}-x_{n}\right\|_{L_{p}}\right)$ against the number of iterations in each case. The computation results can be seen in Table 2 and Figure 2.

Table 1. Computation results for Example 1.

\begin{tabular}{lccccc}
\hline & & UJO alg. (17) & ZMD alg. (6) & Song alg. (5) & AR alg. (4) \\
\hline \multirow{2}{*}{ Case I } & No. of Iter. & 15 & 50 & 26 & 35 \\
& CPU time (sec) & 0.0034 & 0.0168 & 0.0072 & 0.091 \\
\hline \multirow{2}{*}{ Case II } & No. of Iter. & 16 & 49 & 25 & 35 \\
& CPU time (sec) & 0.0029 & 0.0148 & 0.0082 & 0.0089 \\
\hline \multirow{2}{*}{ Case III } & No. of Iter. & 22 & 47 & 24 & 33 \\
& CPU time (sec) & 0.0084 & 0.0113 & 0.0102 & 0.0116 \\
\hline \multirow{2}{*}{ Case IV } & No. of Iter. & 10 & 52 & 27 & 37 \\
& CPU time (sec) & 0.0032 & 0.0125 & 0.0075 & 0.0098 \\
\hline
\end{tabular}

Table 2. Computation results for Example 2.

\begin{tabular}{llll}
\hline & & Algorithm (17) & Algorithm (6) \\
\hline \multirow{2}{*}{ Case I } & No. of Iter. & 2 & 2 \\
& CPU time (sec) & 1.5206 & 4.1734 \\
\hline Case II & No. of Iter. & 2 & 2 \\
& CPU time (sec) & 1.3816 & 5.1309 \\
\hline \multirow{2}{*}{ Case III } & No. of Iter. & 2 & 2 \\
& CPU time (sec) & 2.2795 & 8.5628 \\
\hline Case IV & No. of Iter. & 2 & 2 \\
& CPU time (sec) & 1.8884 & 8.5531 \\
\hline
\end{tabular}



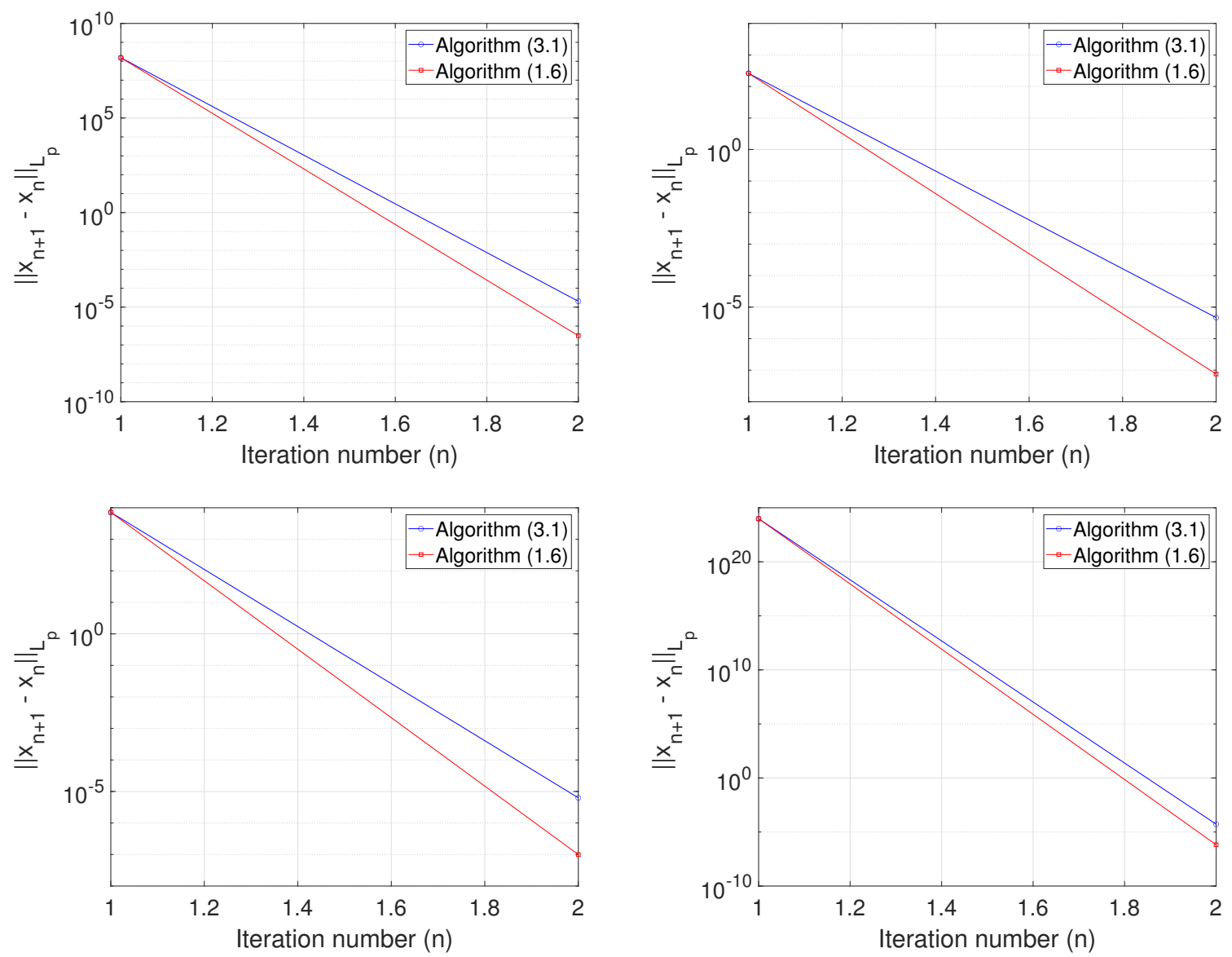

Figure 2. Example 2, Top Left: Case I; Top Right: Case II; Bottom Left: Case III; Bottom Right: Case IV.

Example 3. Next, we apply our result to solve the image restoration problem. We show the performance of our algorithm (17) with iteration (4)-(6). The image restoration problem can modeled as the linear system

$$
b=\mathcal{D} x+e,
$$

where $b \in \mathbb{R}^{M}$ is the observed data with noisy, $e$ is the noise, $\mathcal{D}: \mathbb{R}^{N} \rightarrow \mathbb{R}^{M}(M \ll N)$ is a bounded linear operator, and $x \in \mathbb{R}^{N}$ is the vector with $m$ non-zero components. This problem can also be formulated as the following Least Absolute Shrinkage and Selection Operator (LASSO) problem:

$$
\min _{x \in \mathbb{R}^{N}}\left\{\|\mathcal{D} x-b\|_{2}^{2}+\lambda\|x\|_{1}\right\}
$$

for some regularization parameter $\lambda>0$. Equivalently, the split feasibility problem (1) can be rewritten as

$$
\min _{x \in \mathbb{R}^{N}}\{f(x)+g(x)\}
$$

where $f(x)=\|\mathcal{D} x-b\|_{2}^{2}$ and $g(x)=\lambda\|x\|_{1}$. Following Corollary 1 , we can apply our algorithm for solving the image deblurring problem by setting $A=N_{C}, T=P_{Q}, Q=\{b\}, B=\mathcal{D}$ and $C=$ $\left\{x \in \mathbb{R}^{N}:\|x\|_{1} \leq t\right\}$, where $t>0$. In our experiments, we used the grey test image Cameraman $(256 \times 256)$ and Moon $(537 \times 358)$ in an Image Processing Toolbox in MATLAB, while each test image is degraded by Gaussian $7 \times 7$ blur kernel with standard deviation 4 . In our computation, we take $\alpha_{n} \frac{1}{100 n}, t_{n}=\frac{15}{100}, \beta_{n}=\frac{29 n}{100 n+1}, \lambda=0.25, \alpha=0.04$; for (6), we take $\alpha_{n}=\frac{1}{100 n}, \gamma=0.001$; for (5), we take $\alpha_{n}=\frac{1}{100 n}, \beta_{n}=\frac{1}{3}, \delta_{n}=1-\frac{1}{3}-\alpha_{n}, \gamma=0.001, \eta_{i}=1, i=1, \sigma_{n}=\frac{2 n}{100 n+1}$; for (4), we take $\beta_{n}=\frac{2 n}{100 n+1}$. The maximum number of allowed iterations is set to be 1000 . We compare the quality of the restored image using the signal-to-noise ratio defined as 


$$
S N R=20 \times \log _{10}\left(\frac{\|x\|_{2}}{\left\|x-x^{*}\right\|_{2}}\right),
$$

where $x$ is the original image and $x^{*}$ is the restored image. Typically, the larger the SNR, the better the quality of the restored image. Figures 3 and 4 show the reconstructed images using the iterative algorithms. In Figures 5 and 6, we show the graphs of SNR against number of iterations for each algorithm. In Table 3, we show the time taken by each iteration for reconstruction of the test images.

From Figures 3 and 4, it can be seen that all the algorithms are efficient for restoring the test images. Moreover, from Table 3, the proposed iteration (17) is faster than (4) and (6) with respect to the time taken for restoring the cameraman and tree images.

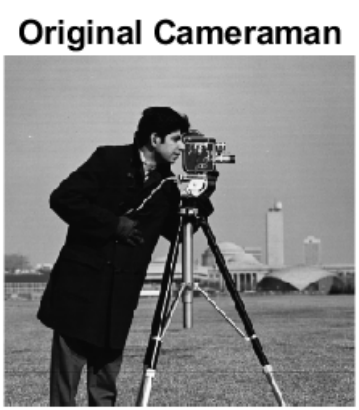

UJO alg.

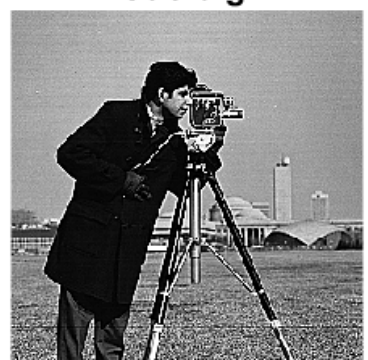

ZMD alg.

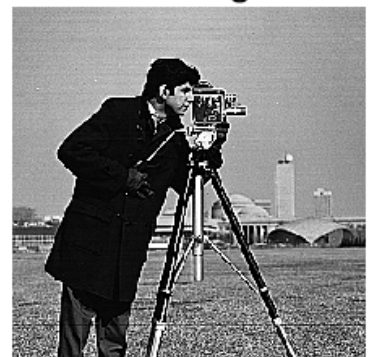

\section{Blurred Cameraman}

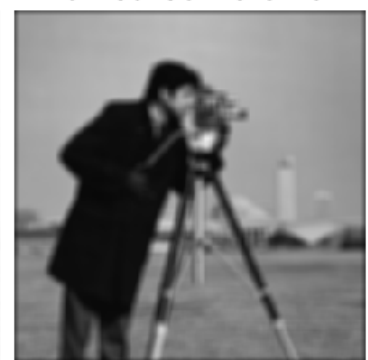

Song alg.

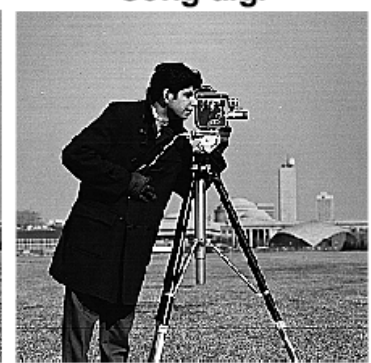

AR alg.

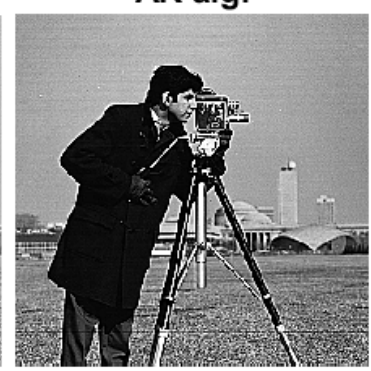

Figure 3. Example 3, Top shows original Cameraman image (left) and degraded Cameraman image (middle), recovered image by iteration (17) (right); Bottom shows image recovered by iteration (6) (left), (5) (middle), and (4) (right).

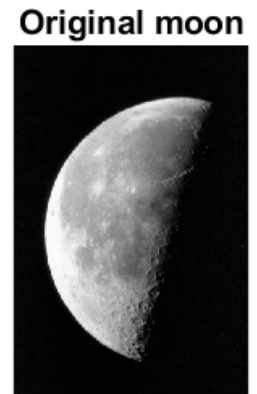

UJO alg.

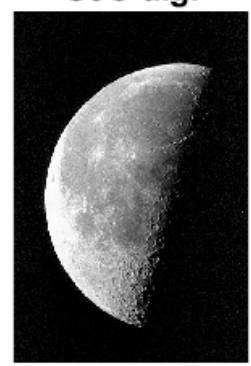

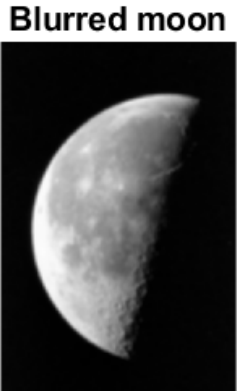

ZMD alg.

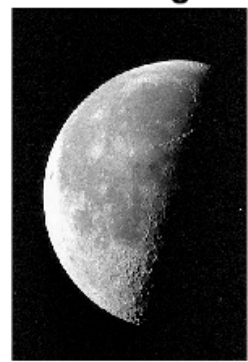

Song alg.

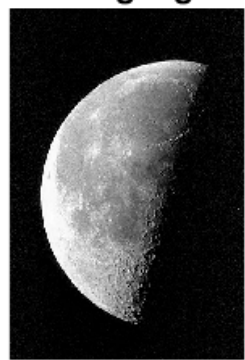

AR alg.

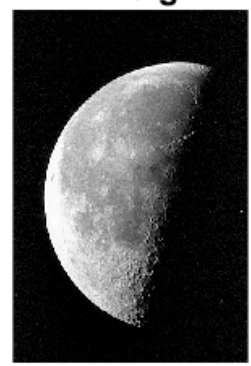

Figure 4. Example 3, Top shows original moon image (left) and degraded moon image (middle), recovered image by iteration (17) (right); Bottom shows image recovered by iteration (6) (left), (5) (middle), and (4) (right). 


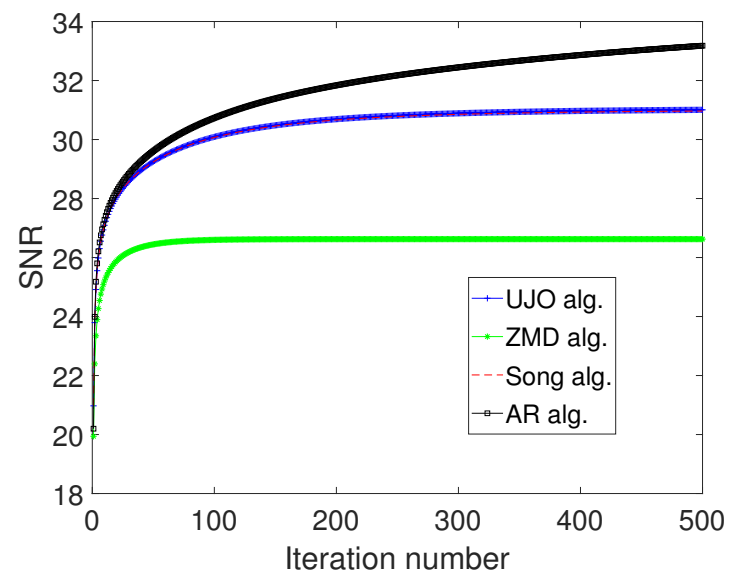

Figure 5. Example 3, Graphs of SNR value for test image cameraman against number of iterations for iteration (17), (6), (5), and (4).

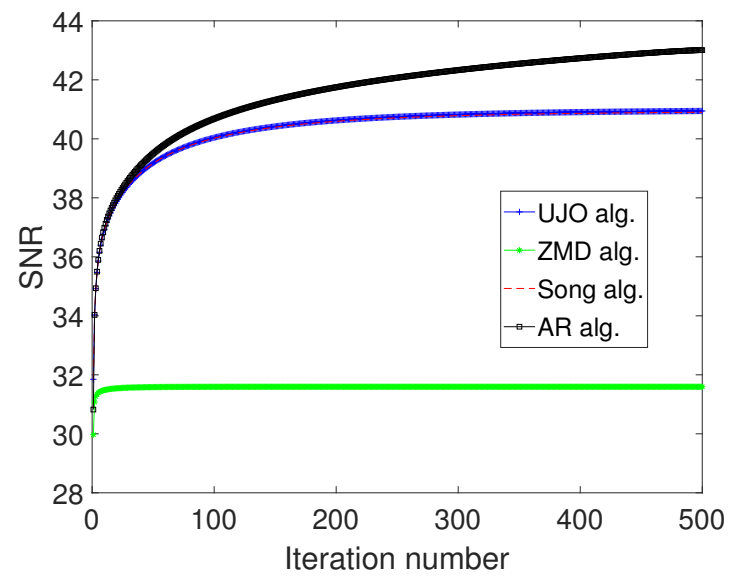

Figure 6. Example 3, Graphs of SNR value for test image cameraman against number of iterations for iteration (17), (6), (5), and (4).

Table 3. Time (seconds) for computing the recovered images in Example 3.

\begin{tabular}{lll}
\hline & Moon & Cameraman \\
\hline UJO alg. (17) & 10.2275 & 20.3075 \\
ZMD alg. (6) & 11.8521 & 39.2120 \\
Song alg. (5) & 10.0642 & 20.1219 \\
AR alg. (4) & 12.2164 & 21.4980 \\
\hline
\end{tabular}

\section{Conclusions}

In this paper, we introduced a new generalized explicit iterative method for solving generalized split feasibility problems in real Banach spaces. The algorithm is designed such that it is stepsize chosen self-adaptively and does not require the prior knowledge of the norm of the bounded linear operator, which is difficult to estimate in general. Furthermore, a strong convergence result is proved and some numerical examples are presented to illustrate the performance of the proposed method. In addition, the algorithm is applied to an image reconstruction problem to show its usefulness and efficiency. 
Author Contributions: Conceptualization, L.O.J.; methodology, G.C.U. and L.O.J.; validation, G.C.U. and L.O.J.; formal analysis, G.C.U. and L.O.J.; writing—original draft preparation, G.C.U.; writingreview and editing, L.O.J. and C.C.O.; visualization, L.O.J.; supervision, G.C.U., L.O.J. and C.C.O.; project administration, G.C.U. and C.C.O.; funding acquisition, L.O.J. All authors approved the final manuscript. All authors have read and agreed to the published version of the manuscript.

Funding: This research was funded by the Sefako Makgatho Health Sciences University Postdoctoral research fund and the APC was funded by the Department of Mathematics and Applied Mathematics, Sefako Makgatho Health Sciences University, Pretoria, South Africa.

Institutional Review Board Statement: Not applicable.

Informed Consent Statement: Not applicable.

Data Availability Statement: Not applicable.

Acknowledgments: The authors acknowledge with thanks the Sefako Makgatho Health Sciences University for providing funds for the research. L.O.J. also thanks the the Federal University of Agriculture, Abeokuta, for hosting him and providing their facilities to support the course of the research.

Conflicts of Interest: The authors declare no conflict of interest. The funders had no role in the design of the study; in the collection, analyses, or interpretation of data; in the writing of the manuscript, or in the decision to publish the results.

\section{References}

1. Censor, Y.; Elfving, T. A multiprojection algorithm using Bregman projection in a product splace. Numer. Algorithms 1994, 8, 221-239. [CrossRef]

2. Byne, C. Iterative obligue projection onto convex sets and the split feasibility problem. Inverse Probl. 2002, 18, 441-453.

3. Censor, Y.; Bortfeld, T.; Martin, B.; Trofimov, T. A unified approach for inversion problem in intensity-modolated radiation therapy. Phys. Med. Biol. 2006, 51, 2353-2365. [CrossRef]

4. Censor, Y.; Elfving, T.; Kopf, N.; Bortfeld, T. The multiple-sets split feasibility problem and its applications. Inverse Probl. 2005, 51, 2071-2084. [CrossRef]

5. Censor, Y.; Motova, A.; Segal, A. Pertured projections and subgradient projections for the multiple-sets split feasibility problems. J. Math. Anal. Appl. 2007, 327, 1244-1256. [CrossRef]

6. Takahashi, W.; Xu, H.K.; Yao, J.C. Iterative methods for generalized split feasibility problems in Hilbert spaces. Set-Valued Var. Anal. 2014, 23, 205-221. [CrossRef]

7. Ansari, Q.H.; Rehan, A. Iterative methods for generalized split feasibility problems in Banach spaces. Carp. J. Math. 2017, 33, 9-26. [CrossRef]

8. Song, Y. Iterative methods for fixed point problems and generalized split feasibility problems in Banach spaces. J. Nonlinear Sci. Appl. 2018, 11, 198-217. [CrossRef]

9. Zi, X.; Ma, Z.; Du, W.S. Strong convergence theorems for generalized split feasibility problems in Banach spaces. Mathematics 2020, 8, 892. [CrossRef]

10. Zhao, J. Solving split equality fixed-point problem of quasi-nonexpansive mappings without prior knowledge of operators norms. Optimization 2015, 64, 2619-2630. [CrossRef]

11. Ke, Y.; Ma, C. The generalized viscosity implicit rules of nonexpansive mappings in Hilbert space. Fixed Point Theory Appl. 2015, 2015, 190. [CrossRef]

12. Hoffman, J.D. Numerical Methods for Engineers and Scientists, 2nd ed.; Marcel Dekker, Inc.: New York, NY, USA, 2001.

13. Palais, R.S.; Palais, R.A. Differential Equations, Mechanics, and Computation; American Mathematical Society: Providence, RI, USA, 2009

14. Marino, G.; Scardamaglia, B.; Zaccone, R. A general viscosity explicit midpoint rule for quasi-nonexpansive mappings. J. Nonlinear Convex Anal. 2017, 18, 137-148.

15. Xu, H.K. Inequalities in Banach spaces with applications. Nonlinear Anal. 1991, 16, 1127-1138. [CrossRef]

16. Cioranescu, I. Geometry of Banach Spaces, Duality Mappings and Nonlinear Problems; Kluwer Academic: Dordrecht, The Netherlands, 1990.

17. Reich, S. A weak convergence theorem for the alternating method with Bregman distance. In Theory and Applications of Nonlinear Operators of Accretive and Monotone Type; Kartsatos, A.G., Ed.; Marcel Dekker: New York, NY, USA, 1996; pp. $313-318$.

18. Takahashi, W. Nonlinear Functional Analysis; Yokohama Publishers: Yokohama, Japan, 2000.

19. Nilsrakoo, W.; Saejung, S. Strong convergence theorems by Halpern-Mann iterations for relatively nonexpansive maps in Banach spaces. Appl. Math. Comput. 2011, 217, 6577-6586. [CrossRef]

20. Matsushita, S.; Takahashi, W. A strong convergence theorem for relatively nonexpansive mappings in Banach spaces. J. Approx. Theory 2005, 134, 257-266. [CrossRef] 
21. Alber, Y.I. Metric and generalized projection operators in Banach spaces: Properties and applications. In Theory and Applications of Nonlinear Operators of Accretive and Monotone Type; Kartsatos, A.G., Ed.; Lecture Notes Pure Appl. Math.; Dekker: New York, NY, USA, 1996; Volume 178, pp. 15-50.

22. Alber, Y.I.; Guerre-Delabriere, S. On the projection methods for fixed point problems. Analysis 2001, 21, 17-39. [CrossRef]

23. Alber, Y.I.; Reich, S. An iterative method for solving a class of nonlinear operator equations in Banach spaces. Panamer. Math. J. 1994, 4, 39-54.

24. Zhou, H.; Gao, E. An iterative method of fixed points for closed and quasi-strict pseudocontractions in Banach spaces. J. Appl. Math. Comput. 2010, 33, 227-237. [CrossRef]

25. Takahashi, W.; Wen, C.F.; Yao, J.C. Strong convergence theorem by shrinking projection method for new nonlinear mappings in Banach spaces and applications. Optimization 2017, 66, 609-621. [CrossRef]

26. Browder, F.E. Browder, Nonlinear maximal monotone operators in a Banach space. Math. Ann. 1968, 175, 89-113. [CrossRef]

27. Kamimura, S.; Takahashi, W. Strong convergence of a proximal-type algorithm in a Banach space. SIAM J. Optim. 2002, 13, 938-945. [CrossRef]

28. Kohsaka, F.; Takahashi, W. Strong convergence of an iterative sequence for maximal monotone operators in a Banach space. Abstr. Appl. Anal. 2004, 2004, 239-249. [CrossRef]

29. Khan, A.R.; Ugwunnadi, G.C.; Makukula, Z.G.; Abbas, M. Strong convergence of inertial subgradient extragradient method for solving variational inequality in Banach space. Carpathian J. Math. 2019, 35, 327-338. [CrossRef]

30. Xu, H.K. Iterative algorithms for nonlinear operators. J. Lond. Math. Soc. 2002, 66, 240-256. [CrossRef]

31. Maingé, P.E. Strong convergence of projected subgradient methods for nonsmooth and nonstrictly convex minimization. SetValued Anal. 2008, 16, 899-912. [CrossRef]

32. Rockafellar, R.T. On the maximality of sums of nonlinear monotone operators. Trans. Am. Math. Soc. 1970, 149, 75-88. [CrossRef]

33. Agarwal, R.P.; Regan, D.O.; Sahu, D.R. Fixed Point Theory for Lipschitzian-Type Mappings with Applications; Springer: Berlin/Heidelberg, Germany, 2009. 